\title{
The Effects of the Heavy Rainfall Event of 12 June 2005 on Taiwan Terrain
}

\author{
Shui-Shang Chi and Guo-Ji Jian * \\ Central Weather Bureau, Taipei, Taiwan, ROC \\ Received 2 March 2008, accepted 23 July 2008
}

\begin{abstract}
A series of numerical simulations are conducted using the Weather Research and Forecasting (WRF-ARW) model with a 9-km mesh to examine the physical processes responsible for the torrential rainfall associated with a mesoscale convective system (MCS) along the Mei-Yu front that caused severe damage over southwestern Taiwan on 12 June 2005. In the control experiment (with full Taiwan terrain), the MCS tends to propagate northward along the windward (western) slope, rather than being advected downstream, as it encounters the southern Central Mountain Range (CMR). The low-level convergence between the dynamically-driven return flow and the incoming southwesterly flow is an important factor for the northward propagation of the MCS. The values of the unsaturated moist Froude number $\left(F_{w}\right)$ and the convective available potential energy (CAPE) are about 0.333 and $2858 \mathrm{~J} \mathrm{~kg}^{-1}$ for the convectively unstable basic flow. This airflow belongs to the flow-around regime as suggested by previous studies. In this flow regime, the torrential rainfall associated with the simulated MCS occurs on both the upslope side and adjacent plains over southwestern Taiwan, which agrees well with the observed rainfall distribution.

A sensitivity study of lowering the Taiwan terrain elevations to $80 \%\left(F_{w} \sim 0.416\right)$ or $60 \%\left(F_{w} \sim 0.555\right)$ of that in the control experiment reveals that the airflow is characterized by a long-lasting orographic convective system near the mountain peaks. The simulated torrential rainfall mainly occurs along the mountain peaks of the southern CMR. The experiment with a reduced elevation to $40 \%\left(F_{w} \sim 0.833\right)$ or $20 \%\left(F_{w} \sim 1.666\right)$ in the control experiment shows a downstream-propagating MCS, which falls into the flow-over regime. This study demonstrates that the northward propagating MCS, which is mainly caused by the flow deflection by southern CMR, played a key role in producing torrential rainfall over southwestern Taiwan during 0000 1200 UTC 12 June 2005.
\end{abstract}

Key word: MCS, Torrential rainfall, Mei-Yu, WRF-ARW

Citation: Chi, S. S. and G. J. Jian, 2009: The effects of the heavy rainfall event of 12 June 2005 on Taiwan terrain. Terr. Atmos. Ocean. Sci., 20, 629-644, doi: 10.3319/TAO.2008.07.23.01(A)

\section{INTRODUCTION}

Mesoscale convective systems (MCSs) frequently propagate from May to June during the annual "plum rains" or "Mei-Yu" season where torrential rains and extensive damage often occur from 4 or 5 slow-moving (sometimes quasistationary) frontal systems (Chen 1983). The MCSs generally move eastward along the Mei-Yu front and then encounter the steep Central Mountain Range (CMR) of Taiwan. Based on intensive observations from about 400 rain gauge stations, the rainfall distribution of 15 May to 15 June in 1992 - 2004 indicates three major precipitation centers (Fig. 1a). Two are on the steep windward (western) slopes of

\footnotetext{
* Corresponding author

E-mail:jgj@cwb.gov.tw
}

Snow and A-Li mountains. The other is found in the GaoPing Shi (River) Valley in southwestern Taiwan, where the heavy orographic rainfall is most frequently observed during the Mei-Yu season. Many studies (e.g., Chen and Yu 1988; Chen 1992; Jou and Deng 1992; Chen and Li 1995; Chen et al. 2005, 2006) demonstrated that heavy rainfall events in Taiwan during the Mei-Yu season are coincident with a southwesterly low-level jet (LLJ) on the warm side of the Mei-Yu front. Lin et al. (2001) and Chiao and Lin (2003) found that the LLJ is an important common ingredient for producing heavy orographic rainfall. The southwesterly LLJ may serve as a conveyor belt that supplies warm and moist (high equivalent potential temperature, $\theta_{e}$ ) air along the upslope side of the CMR, which favors in in- 

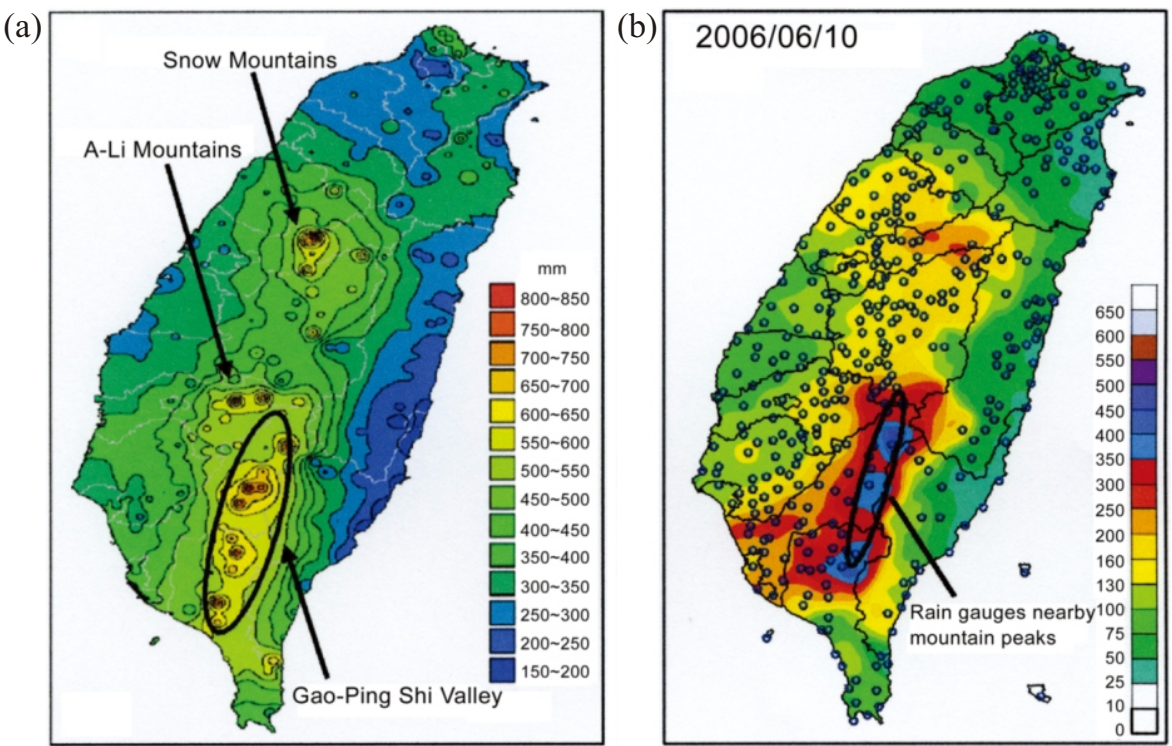

Fig. 1. (a) Rainfall statistics of 15 May - 15 June from 1992 - 2004 based on the intensive observations of the 391 rain gauge stations across Taiwan. (b) The accumulated rainfall associated with a heavy rainfall event on 10 June 2006. The open circles indicate the locations of the rain gauge stations.

ducing the potentially (convectively) unstable layer and the formation of deep convection over orography.

Lin (2007) further found that the extremely heavy orographic rainfall requires significant contributions from any combination of the following nine common ingredients: (1) high precipitation efficiency of the incoming airstream, (2) a low-level jet, (3) steep orography, (4) favorable (e.g., concave) mountain geometry and a confluent flow field, (5) strong synoptically-forced upward vertical motion, (6) a moist unstable low-level flow, (7) a high moisture flow upstream, (8) presence of a large, pre-existing convective system, and (9) slow or impeded movement of the convective system. In southwestern Taiwan, the torrential rainfall events in the Gao-Ping Shi Valley are often initiated in such a concave region since the strong vertical motion can be produced if the incoming moist airstream is confluent, as indicated by the fourth ingredient.

Determining the location of heavy orographic rainfall is a rather challenging scientific and forecasting issue. According to the intensive observations in the Taiwan Area Mesoscale Experiment (TAMEX; Kuo and Chen 1990), the heaviest rainfall may occur on either the windward slope or over a plain area (e.g., Jou 1997). Chen et al. (1991) presented an orographically induced precipitation system that triggered continuously new cells on the western slope of the northern CMR on 7 June 1987 during TAMEX (IOP 8). On the other hand, Yeh and Chen (2002) studied a coastal rainfall case on 22 May 1987 and suggested that the offshore convergence enhanced by the orographic blocking and the prevailing southwesterly flow was important for the occurrence of heavy rainfall along the northwestern coast of Taiwan. Wang et al. (2005) found that the terrain-induced convergence zone upstream of the CMR is sensitive to terrain height and plays an important role in determining the location of heavy rainfall. Based on two-dimensional idealized simulations, Chen and Lin (2005a) extended Chu and Lin (2000) study and proposed that the propagation and types of convective systems are controlled by the convective available potential energy (CAPE) and the unsaturated moist Froude number $\left(F_{w}=U / N_{w} h\right)$, where $U$ is the upstream basic wind speed near the mountain, $N_{w}$ is the unsaturated moist Brunt-Väisälä frequency, and $h$ is the mountain height. They identified four moist flow regimes for a conditionally unstable flow passing over a mesoscale mountain ridge. In regime I, a convective system present early in the vicinity of the mountain peak propagated upstream against the basic flow. In regime II, a long-lasting convective system may appear over the mountain peak, upslope or on the lee slope. In regime III, a downstream-propagating convective system or mixed convective and stratiform rainfall system over the mountain is present. In regime IV, an orographic stratiform rainfall system over the mountain or a downstream-propagating cloud system may occur. When $U$ is fixed, the increase (decrease) of CAPE is equivalent to the shifting to higher (lower) $F_{w}$ flow regime.

On 12 June 2005, a quasi-stationary Mei-Yu front was active and produced torrential rainfall on the windward (western) slope and the plain area that resulted in severe damage over southwestern Taiwan with rainfall in excess of $500 \mathrm{~mm}$ within $24 \mathrm{~h}$. Early in the event, a MCS that eventually produced the heavy rainfall first developed around 1800 UTC 11 June 2005 over the southern Taiwan Strait. The MCS propagated toward Taiwan and produced accumulated rainfall up to $\sim 255 \mathrm{~mm}$ over the southwestern part of Taiwan between 0000 and 1200 UTC 12 June 2005 (to be further described in section 2a). Many previous studies have also ad- 
dressed similar severe weather events in other regions, such as Japan, China, and Korea (e.g., Watanabe and Ogura 1987; Yoshizaki et al. 2000). The uniqueness of the current case study is twofold. First, the 4-h rainfall amount exceeded 220 mm over southwestern Taiwan. The peak hourly precipitation rate was as high as $68.5 \mathrm{~mm}$. In terms of real-time quantitative precipitation forecasts, the rainfall amount cited above is exceptionally high. Second, the rainfall statistics (Fig. 1a) and several other heavy rainfall events during Mei-Yu season (e.g., the event happened on 10 June 2006, see Fig. 1b) indicate that rainfall accumulation measured by rain gauges are largest along the mountain peaks (the rain gauges located near the mountain peaks in southern Taiwan are marked in Fig. 1b). It will be shown later in Fig. 6a that the heaviest rainfall in the current case study occurred on the windward slope rather than over the mountain peaks, which poses a rather important scientific and forecasting problem. In order to understand the effects of the CMR on the heavy rainfall event of 12 June 2005, a series of numerical simulations are performed using the newly developed Advanced
Research version of the Weather Research and Forecasting (WRF-ARW) model (Skamarock et al. 2005). In this study, the following questions are addressed: (1) What is the evolution of the MCS when encountering the CMR? (2) What is the role played by the Taiwan terrain? (3) What is the impact of terrain height (i.e., represented by $F_{w}$ ) on the rainfall distributions over southwestern Taiwan? This paper is organized as follows. Section 2 describes the synoptic situations, the numerical model setup, and experiment design. Results of numerical simulations are discussed in section 3. A summary is then provided in section 4 .

\section{SYNOPTIC OVERVIEW, MODEL DESCRIPTION, AND EXPERIMENT DESIGN}

\subsection{Brief Synoptic Overview of the Heavy Rainfall Event of 12 June 2005}

Synoptic weather charts at surface on 12 - 13 June 2005 (Figs. 2a, c) show that a Mei-Yu front extended from (a) $2005 / 06 / 12 / 00 Z$

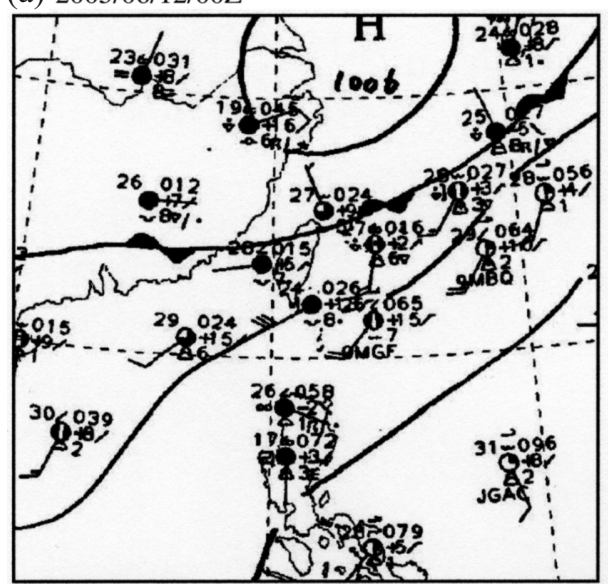

(c) $2005 / 06 / 13 / 00 Z$

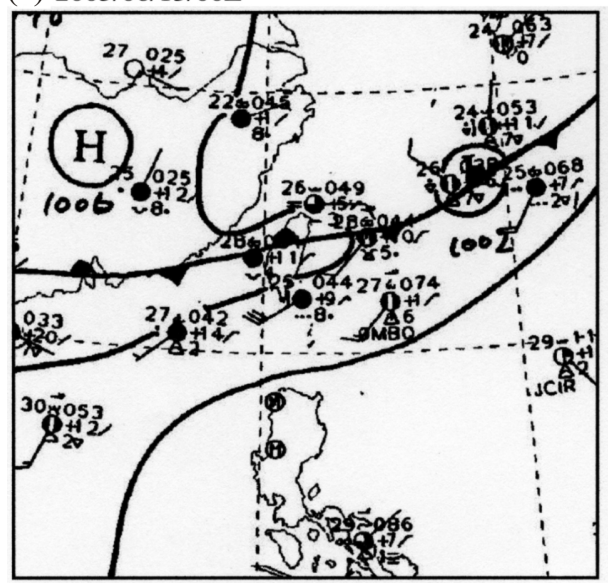

(b) $2005 / 06 / 12 / 00 Z$

$12 \mathrm{~h}$

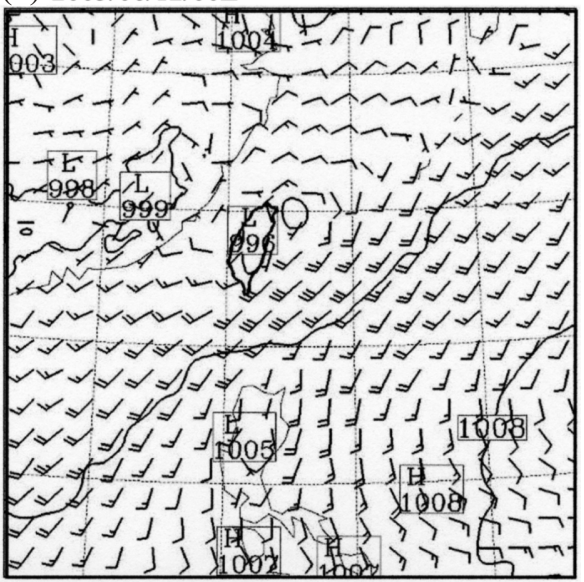

(d) $2005 / 06 / 13 / 00 Z$

$36 \mathrm{~h}$

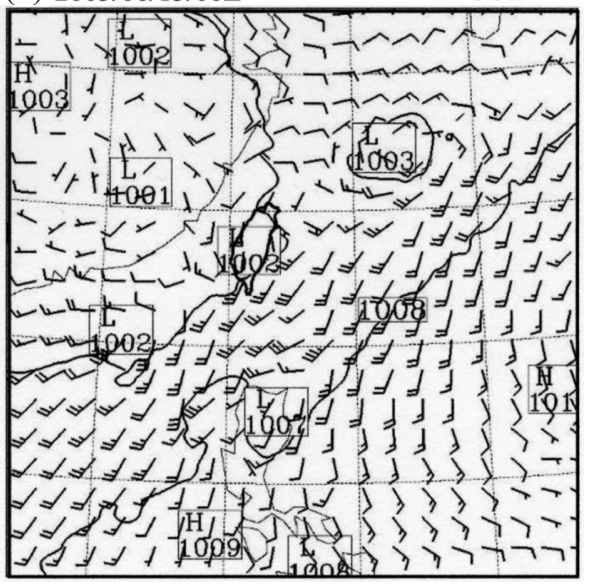

Fig. 2. Synoptic weather maps at surface for (a) 0000 UTC 12 June and (c) 0000 UTC 13 June 2005. Surface observations are plotted conventionally. Simulated wind vectors (half barb $=2.5 \mathrm{~m} \mathrm{~s}^{-1}$ and full barb $=5 \mathrm{~m} \mathrm{~s}^{-1}$ ) at the lowest model level and sea-level pressure (contour interval of $4 \mathrm{hPa}$ ) from CTRL at (b) 0000 UTC 12 June and (d) 0000 UTC 13 June 2005. 
northeast to southwest passing through northern Taiwan and remained nearly stationary. The prevailing wind over the South China Sea and southwestern Taiwan was southwesterly, with a wind speed of approximately $5-7.5 \mathrm{~m} \mathrm{~s}^{-1}$. At $850 \mathrm{hPa}$, the prefrontal wind fields at 0000 UTC 12 June (Fig. 3a) also show southwesterly from the open ocean to Taiwan. The backing of winds with height over postfrontal area (e.g., the sea surrounding northern Taiwan in Figs. 2a and $3 \mathrm{a}$ ) indicates cold air advection after frontal passage. The dewpoint depression values were less than $3 \mathrm{~K}$ at $850 \mathrm{hPa}$ (Fig. 3a), suggesting that the low-level southwesterly flow was rather moist. Figure 4 shows the sounding at 0000 UTC 12 June at the Tungsha station (denoted by an arrow in Fig. 3a). The sounding contains a very high CAPE value of $\sim 2858 \mathrm{~J} \mathrm{~kg}^{-1}$ and a relatively low LFC (the level of free convection) height of $\sim 0.8 \mathrm{~km}$ with an almost saturated atmosphere near the surface. The temperature curve leans to the left of the moist adiabats below $500 \mathrm{hPa}$, indicating that the lower troposphere was convectively unstable. This is a favorable condition for a deep convection to occur.

A sequence of the infrared satellite images is shown in Fig. 5. At 1800 UTC 11 June (Fig. 5a), a MCS formed on the Mei-Yu front over southern Taiwan Strait along the southwesterly flow. The MCS was developing while it was propagating toward the southern CMR (Fig. 5b), where the highest altitude is about $2500 \mathrm{~m}$. As the MCS moved inland, it appears to weaken gradually over the island (Fig. 5c) rather than propagate downstream during the following few hours. More than $250 \mathrm{~mm}$ of 12-h accumulated rainfall ending at 1200 UTC 12 June 2005 has been observed during the event (a) $850 \mathrm{hPa}$

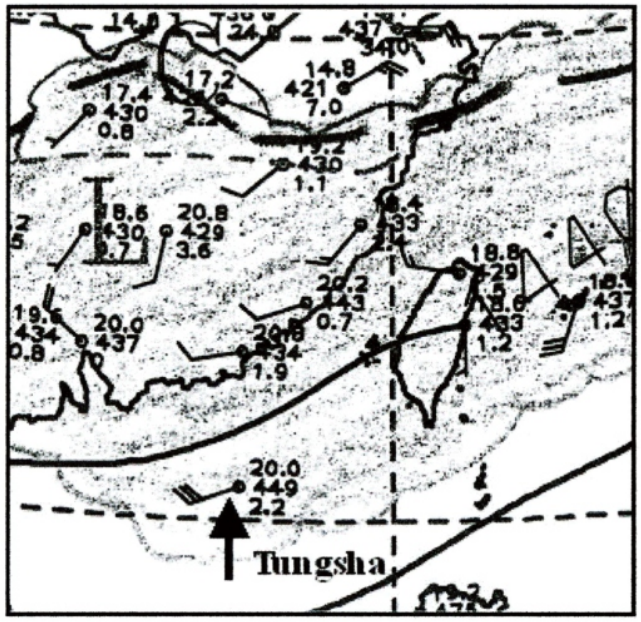

(c) Vertical cross section of potential instabilly

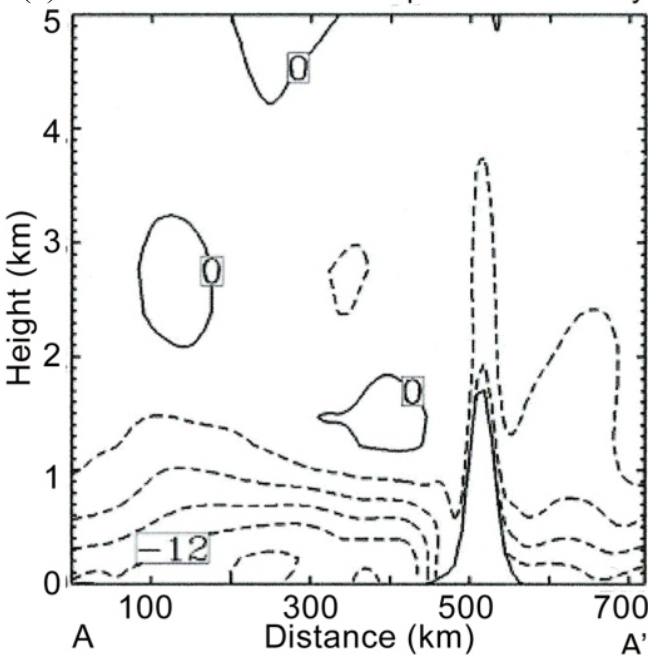

(b) CTRL $850 \mathrm{hPa}$

$2005 / 06 / 12 / 00 Z$

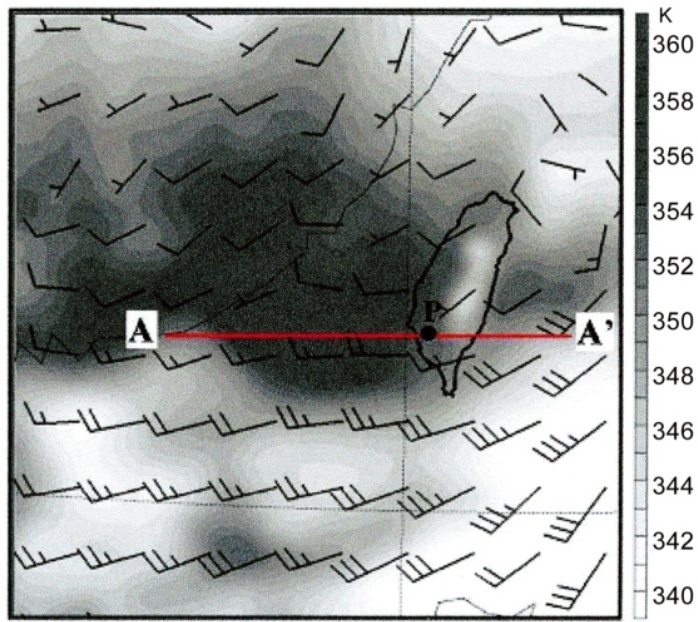

(d) Skew-T diagram 2005/06/12/00z

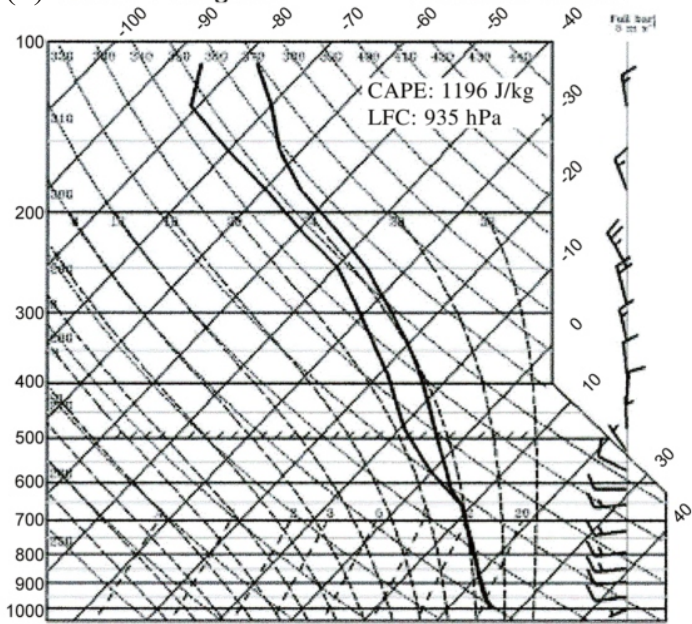

Fig. 3. (a) 850 -hPa heights (solid lines every 3 dam). Station observations are plotted conventionally. The shaded area indicates the dewpoint depression (dry-bulb temperature minus dewpoint temperature) $<3 \mathrm{~K}$. (b) Simulated wind vectors (half barb $=2.5 \mathrm{~m} \mathrm{~s}^{-1}$ and full barb $=5 \mathrm{~m} \mathrm{~s}^{-1}$ ) and equivalent potential temperature (shaded beginning at $340 \mathrm{~K}$ according to the grayscale bar) at $850 \mathrm{hPa}$ from CTRL at (b) 0000 UTC 12 June. (c) The vertical cross section of the vertical gradient of equivalent potential temperature $\left(\mathrm{K} \mathrm{km}^{-1}\right)$ along the AA'. (d) Simulated sounding in skew T-logp format from CTRL at location P in (b). The values of CAPE $\left(\mathrm{J} \mathrm{kg}^{-1}\right)$ and LFC (hPa) are shown in the upper-right corner. The arrow in (a) indicates the location of Tungsha station. 


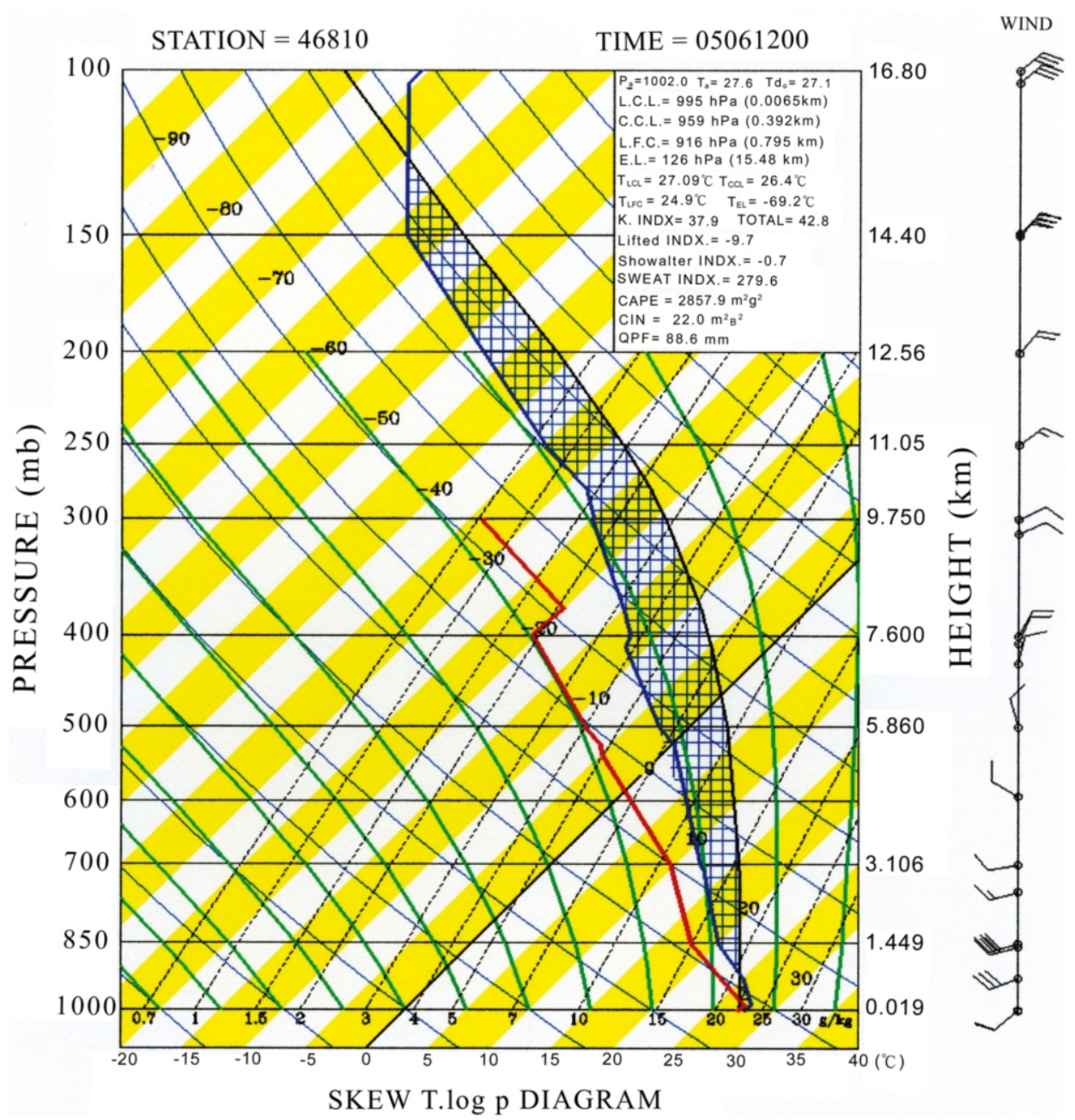

Fig. 4. The skew $T$ - $\log$ P diagram of Tungsha (46810) at 0000 UTC 12 June 2005.
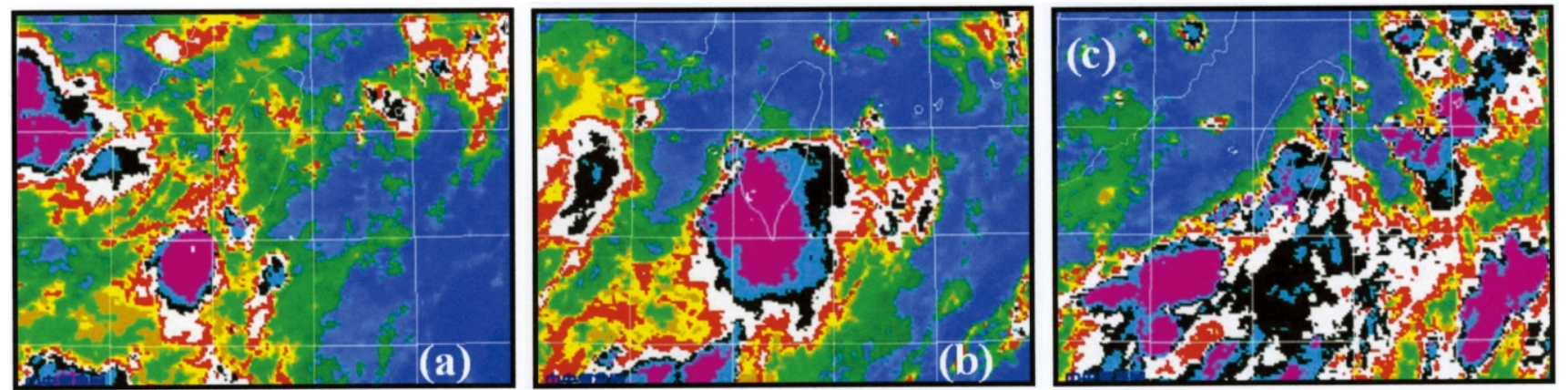

Fig. 5. Sequence of Meteorological Satellite (MTSAT) IR satellite imagery showing a MCS associated with a Mei-Yu front over southwestern Taiwan at (a) 1800 UTC 11, (b) 0000 UTC 12, and (c) 0600 UTC 12 June 2005.

(Fig. 6a) and produced severe damage in southern Taiwan. The relatively heavier rainfall amounts (e.g., exceeding $100 \mathrm{~mm}$ in the $12-\mathrm{h}$ period) on both the windward slope and the plain area, which may implicate a possible influence of Taiwan terrain on the MCS, are of particular interest for this work. In contrast, there was no significant precipitation on the lee (east) side of the Taiwan terrain.

\subsection{Model Configuration and Initial Conditions}

The numerical experiments presented in this study have been conducted with the WRF-ARW modeling sys- 
(a) $06 / 1200 Z \sim 06 / 1212 Z$ Obs.

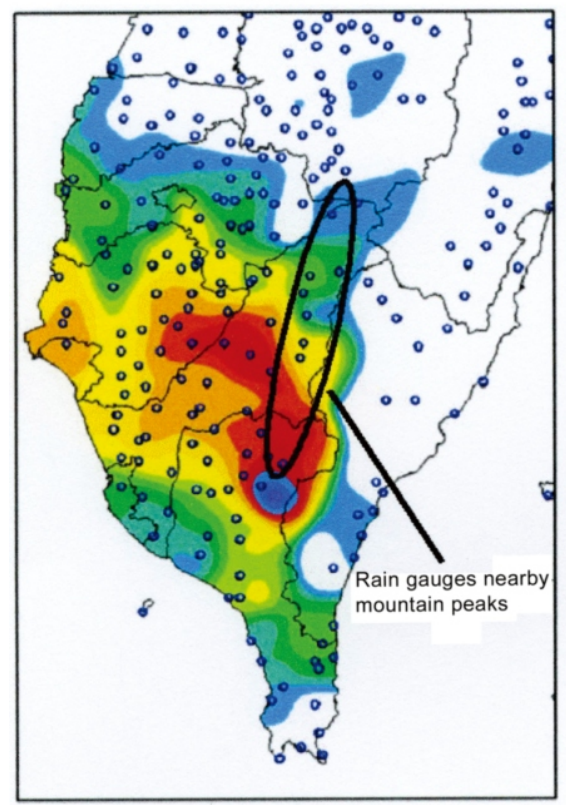

(b) $06 / 1200 Z \sim 06 / 1212 Z \quad C T R L$

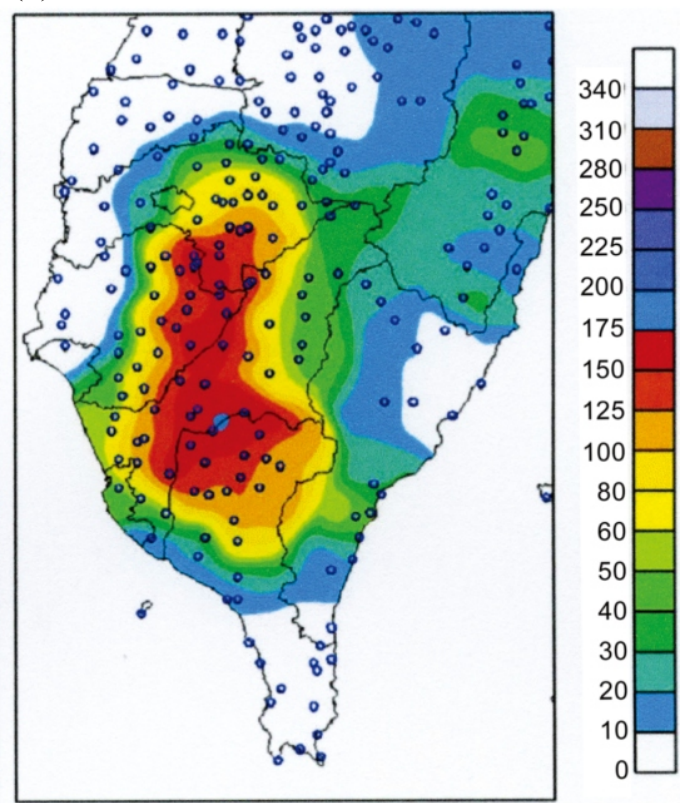

Fig. 6. The accumulated rainfall associated with a MCS over southern Taiwan during the 12 - 13 June heavy rainfall event: (a) observed at 0000 1200 UTC 12 June 2005 and (b) simulated from CTRL at the same time period as in (a). The open circles indicate the locations of the rain gauge stations across Taiwan.

tem, version 2.0.3 (Skamarock et al. 2005). The WRFARW system solves the compressible, non-hydrostatic, fluxform Euler equations in a terrain-following, hydrostaticpressure vertical coordinate $(\eta)$. The model domain has an area of $2250 \mathrm{~km}$ by $2250 \mathrm{~km}$ with 251 by 251 horizontal grid points at $9-\mathrm{km}$ grid spacing (Fig. $2 \mathrm{~b}$ ). Thirty-one $\eta$ levels are used in the vertical, with 8 levels in the lowest $1 \mathrm{~km}$. The model topography is interpolated from terrain data with 30" resolution. Information on land use is obtained from the US Geological Survey (USGS) with the same resolution as for the topography. The physics of the model include the WRF single-moment five-class microphysics (Hong et al. 2004), the Kain-Fritsch convective parameterization scheme (Kain 2004), Yonsei University planetary boundary layer (PBL) scheme (Hong et al. 2003), fivelayer soil model (Chen and Dudhia 2003), Rapid Radiative Transfer Model longwave radiation scheme (Mlawer et al. 1997), and Dudhia shortwave radiation scheme (Dudhia 1989). The model initial conditions are taken from the operational Nonhydrostatic Forecasting System (NFS) analyses at the Central Weather Bureau (CWB) which are made available every $12 \mathrm{~h}$ on a $15 \mathrm{~km} \times 15 \mathrm{~km}$ grid. The lateral boundary conditions are obtained from the operational NFS forecast at 6-h intervals. As to the initialization methods for the CWB-NFS model, the optimum interpolation (OI) objective analysis (Liou et al. 1997) is applied using sounding data, surface observations, pilot balloon wind and aircraft meteorological reports into the CWB global model data for generating the initial conditions of the CWB-NFS model.
In addition, researchers at the CWB are currently working on a more-advanced three-dimensional variational analysis method, which will be applied to replace the OI technique in the near future.

\subsection{Design of Numerical Experiments}

A series of 48-h integration experiments are initialized at 1200 UTC 11 June 2005. Details of all the experiments are described as follows. Comparisons among the following sensitivity numerical experiments are expected to improve our understanding of the impact of Taiwan terrain on the torrential rainfall event of 12 June 2005.

- CTRL: this control experiment includes the complete Taiwan terrain. Initial atmospheric conditions and lateral boundary conditions are provided by the CWB NFS model. Daily sea surface temperatures are obtained from the National Centers for Environmental Prediction (NCEP) and are interpolated to the WRF model grid using the WRF standard initialization programs (WRFSI; see http:// www.mmm.ucar.edu/wrf/users/docs/user_guide old lusers guide chap $3 . \mathrm{html}$ ).

- $\mathrm{H} 80, \mathrm{H} 60, \mathrm{H} 40$, and $\mathrm{H} 20$ : these experiments are the same as in CTRL, except that the terrain height of Taiwan at each grid point is reduced to $80,60,40$, and $20 \%$ of that in CTRL, respectively.

- FLAT: this experiment is the same as in CTRL, except that the Taiwan terrain is set to 1-m elevation, while the land-sea attributes remain unchanged. 
For the volume originally occupied by the CMR in the reduced-terrain experiments, the atmospheric conditions are generated by vertically interpolating CWB-NFS analyses to the model grid points through the WRFSI processing package, except that the initial ground temperature for these sensitivity tests are adjusted from CTRL according to the terrain height with a lapse rate of $-0.6 \mathrm{~K}(100 \mathrm{~m})^{-1}$ (Dodson and Marks 1997). Since the moist-adiabatic lapse rate $\left(\Gamma_{\mathrm{m}}\right)$ is quite sensitive to temperature $(\mathrm{T})$ [For example, at $\mathrm{T}=273 \mathrm{~K}$, $\Gamma_{\mathrm{m}}=-0.69 \mathrm{~K}(100 \mathrm{~m})^{-1}$ and at $\mathrm{T}=303 \mathrm{~K}, \Gamma_{\mathrm{m}}=-0.36 \mathrm{~K}(100 \mathrm{~m})^{-1}$, both at the standard sea-level pressure of $1000 \mathrm{hPa}$ ] (Arya 1988), the used lapse rate of $-0.6 \mathrm{~K}(100 \mathrm{~m})^{-1}$ for the initial adjustment is between the dry-air adiabatic lapse rate $\left[\sim-0.98 \mathrm{~K}(100 \mathrm{~m})^{-1}\right]$ and the moist-adiabatic lapse rate at $\mathrm{T}$ $\sim 300 \mathrm{~K}\left[\sim-0.4 \mathrm{~K}(100 \mathrm{~m})^{-1}\right]$. Using this initialization procedure, there is no unreasonable perturbations during the first few hours of the model integration in the reduced-terrain experiments. The MCSs in the current study formed in a convectively unstable environment with CAPE value of more than $2800 \mathrm{~J} \mathrm{~kg}^{-1}$ (Fig. 4). The values of $F_{w}$ for airflow with $U=7.5 \mathrm{~m} \mathrm{~s}^{-1}$ (will be described further in the next section) and $N_{w}=0.009 \mathrm{~s}^{-1}$ over the southern CMR in CTRL $(h=2500 \mathrm{~m}), \mathrm{H} 80, \mathrm{H} 60, \mathrm{H} 40$, and $\mathrm{H} 20$ are 0.333 , $0.416,0.555,0.833$, and 1.666 , respectively.

\section{RESULTS}

\subsection{Experiment CTRL}

The control experiment, denoted by CTRL, is also compared with observations for validation. After the 12-h forecast, the simulated mean sea-level pressure (MSLP) and wind fields by CTRL (Fig. 2b) are in good agreement with the surface analyses (Fig. 2a). The sea-level Mei-Yu front extended from east-northeast to west-southwest and passed through northern Taiwan. A frontal disturbance formed over the sea northeast of Taiwan. This low developed and moved near the sea southwest of Japan at 0000 UTC 13 June along the front (Fig. 2d). During this 24-h period, both the CTRL and the analyses (Figs. 2c, d) show that the Mei-Yu front remained nearly stationary over Taiwan.

At $850 \mathrm{hPa}$, the simulated prevailing wind (Fig. 3b) in the northern South China Sea was southwesterly at 0000 UTC 12 June, with a wind speed of approximately $10-13 \mathrm{~m} \mathrm{~s}^{-1}$, which is comparable to the observation (Fig. 3a). In the southern Taiwan Strait, the simulated results in CTRL suggest that the flow is more west-southwesterly with relatively low wind speed $\left(7-10 \mathrm{~m} \mathrm{~s}^{-1}\right)$ and high values of equivalent potential temperature at $850 \mathrm{hPa}$ (exceeding $356 \mathrm{~K}$; see Fig. 3b). A vertical cross section of the vertical gradient of equivalent potential temperature $\left(\partial \theta_{e} / \partial z ; \mathrm{K} \mathrm{km}^{-1}\right)$ taken along an east-west direction through southern Taiwan (line AA' in Fig. 3b) is shown in Fig. 3c, which is a measure of convective instability: larger (smaller) negative values of $\partial \theta_{e} / \partial z$ indicate more (less) convectively unstable layers.
This stability parameter is useful in forecasting since it implies regions that may be conducive to severe weather. Figure 3c suggests that the region of convective instability is mainly located below a level of about $1.0 \mathrm{~km} \mathrm{MSL}$. A shallow layer of strong convective instability $\left(\partial \theta_{e} / \partial z<\right.$ $-15 \mathrm{~K} \mathrm{~km}^{-1}$ ) near the surface is simulated about $200 \mathrm{~km}$ upstream of the island, which indicates that the low-level southwesterly flow was transporting convectively unstable, moist air eastward toward Taiwan. A model sounding taken near the plain area of southwestern Taiwan (location marked as "P" in Fig. 3b) at 0000 UTC 12 June is plotted in Fig. 3d. The sounding shows a saturated boundary layer with convective instability below $800 \mathrm{hPa}$. The temperature profile closely follows the moist adiabats from $800 \mathrm{hPa}$ through 650 $\mathrm{hPa}$. These characteristics of the simulated environment are favorable for the development of MCSs along the Mei-Yu front. According to the vertical profile of horizontal wind in Fig. 3d, the estimated value of $F_{w}$ associated with the southwesterly flow over southwestern Taiwan is about 0.333 in the CTRL experiment $\left(U \sim 7.5 \mathrm{~m} \mathrm{~s}^{-1}, N_{w} \sim 0.009 \mathrm{~s}^{-1}\right.$, and $h$ $\sim 2500 \mathrm{~m}$ ).

The simulated accumulated rainfall during 0000 1200 UTC 12 June (Fig. 6b) reaches a maximum of about $200 \mathrm{~mm}$ over the southern CMR's windward slope, which agrees quite well with the observed maximum accumulated rainfall ( $\sim 255 \mathrm{~mm})$ as shown in Fig. 6a. The CTRL realistically simulated the areal distribution of the heavy rainfall in the southwestern part of Taiwan; but the model precipitation extends farther to the east, whcih results in overforecasts over eastern Taiwan. This overforecast error can be examined by comparing the observed radar reflectivity with the simulated results from CTRL (Fig. 7). As is shown in both the radar echo (Fig. 7a) and the precipitation (Fig. 6a), the rainfall amount is much less over eastern Taiwan, where is the rain shadow area on the leeside in this heavy rainfall event. However, the simulated radar echo (Fig. 7b) and raining area pass over the CMR in the CTRL experiment which fails to predict the rain shadow effect observed over eastern Taiwan. One of the major reasons for the above error is that a 9-km grid size is not fine enough to resolve the terrain features responsible for the rain shadow on the lee (east) side of the the CMR. We expect that a finer, more detailed rainfall distribution could be obtained for numerical simulations when a higher resolution is applied in the future. Despite this high bias, the simulation results still provide useful information for evaluating the physical processes of the influence of southern CMR on the MCS. This torrential rainfall event is primarily related to a propagating $\mathrm{MCS}$, as shown by the satellite images (Fig. 5). The horizontal divergence fields at $\eta=0.993$ (the lowest model level) and $300 \mathrm{hPa}$ during 0400 - 1000 UTC at 2-h intervals are plotted in Fig. 8. A low-level convergence region associated with the simulated MCS is found along the windward slope of southern CMR. The magnitude of this convergence region, which decreases 
(a) $06 / 1212 Z$

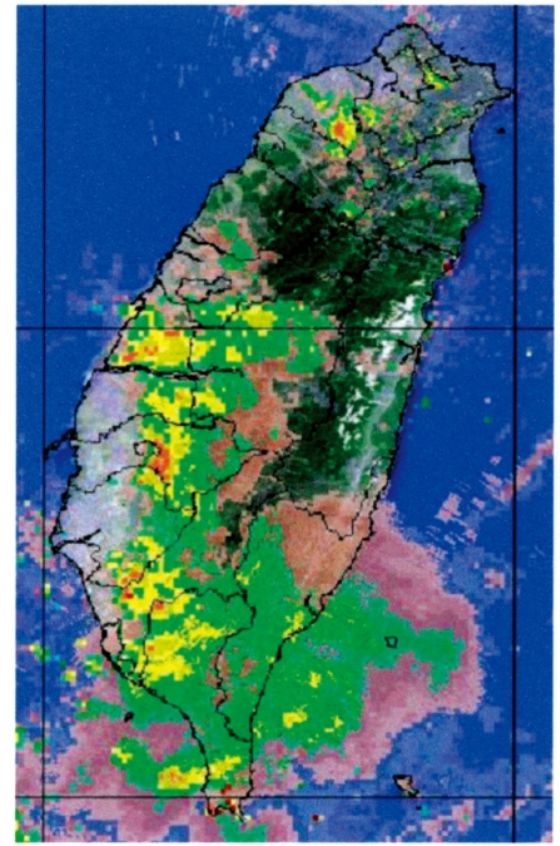

Obs.

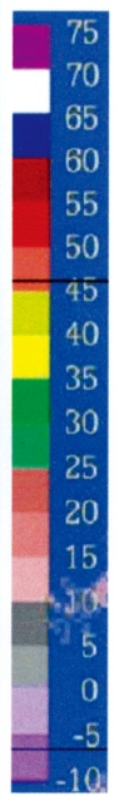

(b) $06 / 1212 Z$

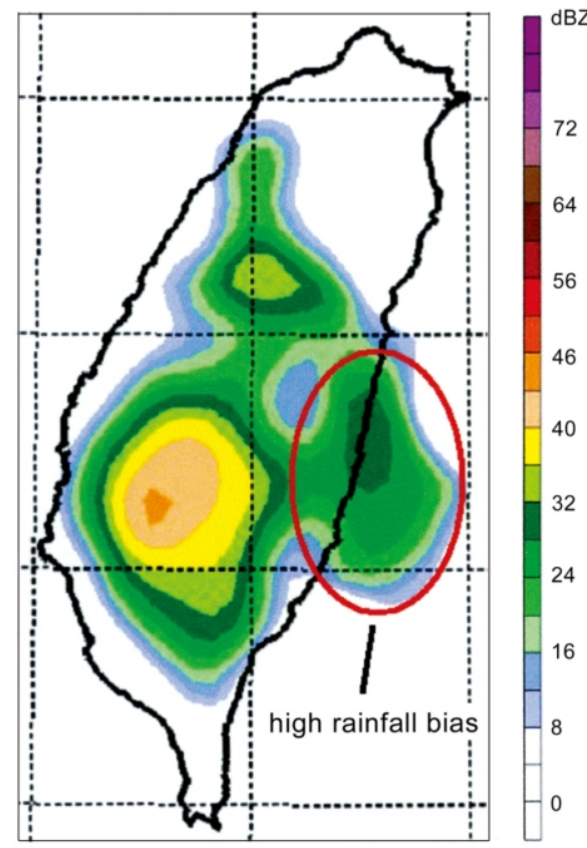

Fig. 7. (a) Composite of vertical maximum values of radar reflectivity (dBZ) at 1200 UTC 12 June 2005. (b) simulated radar reflectivity (composite of vertical maximum values: dBZ) from CTRL at the same time as in (a).
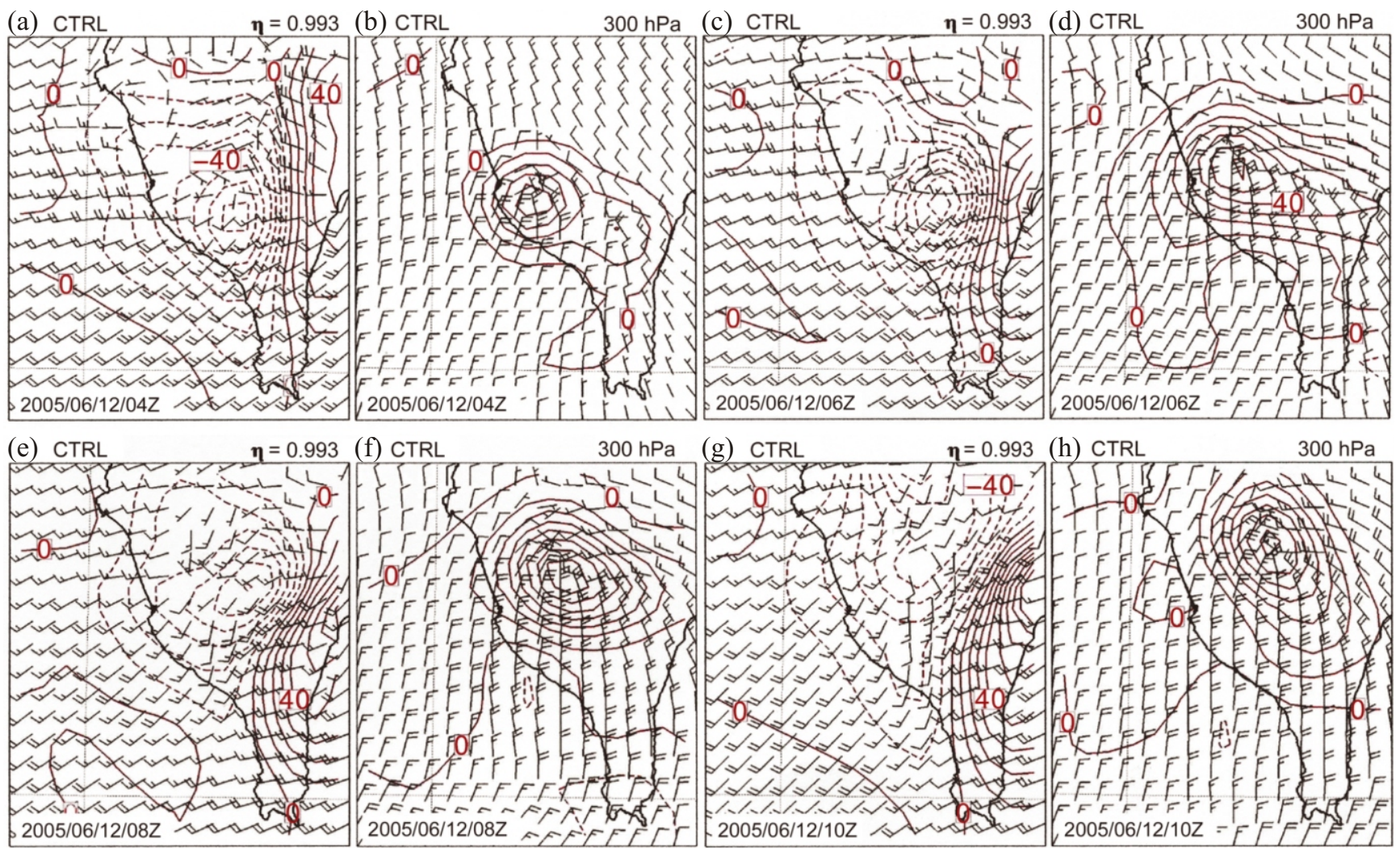

Fig. 8. Simulated wind vectors (half barb $=2.5 \mathrm{~m} \mathrm{~s}^{-1}$ and full barb $=5 \mathrm{~m} \mathrm{~s}^{-1}$ ) and horizontal divergence fields (with contour interval of $10 \times 10^{-5} \mathrm{~s}^{-1}$ ) in CTRL on 12 June 2005: (a) $\eta=0.993$ at $0400 \mathrm{UTC}$, (b) $300 \mathrm{hPa}$ at $0400 \mathrm{UTC}$, (c) $\eta=0.993$ at $0600 \mathrm{UTC}$, (d) $300 \mathrm{hPa}$ at $0600 \mathrm{UTC}$, (e) $\eta=0.993$ at $0800 \mathrm{UTC}$, (f) $300 \mathrm{hPa}$ at $0800 \mathrm{UTC}$, (g) $\eta=0.993$ at $1000 \mathrm{UTC}$, and (h) $300 \mathrm{hPa}$ at $1000 \mathrm{UTC}$. 
from 0400 to 1000 UTC (Figs. 8a, c, e, and g), appears to be related to the evolution of the MCS observed on the satellite images (Figs. 5b, c). This convergence zone is characterized by positive CAPE of about $1196 \mathrm{~J} \mathrm{~kg}^{-1}$ (Fig. 3d). The 300-hPa divergence fields (Figs. 8b, d, f, and h) show a divergence maximum over southwestern Taiwan. This upperlevel divergence in the region is linked to the low-level convergence, and appears to couple with the low-level convergnece to trigger and/or sustain the MCSs; it thus might play a role in producing torrential rainfall.

Chen and Lin (2005a) performed idealized simulations for a conditionally unstable flow over a two-dimensional mountain ridge and found that the propagation of cloud/precipitation systems is controlled by an unsaturated $F_{w}$ and CAPE. Furthermore, Chen and Lin (2005b) suggested that the three-dimensional flow regimes are also controlled by the unsaturated $F_{w}$. They proposed the three-dimensional flowaround regime corresponds to two-dimensional flow regime I as classified by Chen and Lin (2005a), while the flow-over regime corresponds to either two-dimensional flow regime II or III. Figures $8 \mathrm{a}$ and $\mathrm{b}$ show that the southwesterly winds in CTRL are deflected by the CMR, with a weak return flow $\left(\sim 2.5 \mathrm{~m} \mathrm{~s}^{-1}\right)$ at lowest model level over the northern side of the MCS. This low-level convergence between the dynamicallydriven return flow and the incoming southwesterly flow is favorable for the northward propagation of a convective system. As a result, the MCS in CTRL propagates northward along the slope of the southern CMR as illustrated by the time sequence of rainwater mixing ratio (Fig. 9; in units of $\mathrm{g} \mathrm{kg}^{-1}$ ) at $z=1 \mathrm{~km}$. When the Taiwan terrain is removed (experiment FLAT), the MCS propagates downstream (toward the eastnortheast) along the Mei-Yu front at a speed of about $5-6 \mathrm{~m} \mathrm{~s}^{-1}$ (Fig. 10). The differences between the CTRL and FLAT experiments suggest that Taiwan's terrain plays a key role in this MCS movement. In the CTRL experiment, a "flow-around" regime upstream of the CMR is presented at low levels. The $F_{w}$ and the background CAPE are 0.333 and $2858 \mathrm{~J} \mathrm{~kg}^{-1}$, which falls into regime I as proposed by Chen and Lin (2005a) and, therefore, the heavy rainfall is produced over the upslope side of the CMR and adjacent plains (Fig. 6).

\subsection{Sensitivity to the Terrain Height}

Four sensitivity experiments, denoted as H80, H60, $\mathrm{H} 40$, and $\mathrm{H} 20$, are conducted in which the terrain height of Taiwan at each grid is reduced to $80,60,40$, and $20 \%$ of the actual terrain height in CTRL, respectively, to investigate the impact of the Taiwan terrain on the propagation of simulated MCS, and the corresponding rainfall amount and distribution.

The sensitivity of the simulated horizontal divergence fields and wind vectors at the lowest model level to the varying the terrain height of Taiwan can be compared between Figs. 11 and 8. When the terrain height is reduced in the H80 and H60 experiments, the magnitudes of the low-level convergence at 0600 UTC (see Figs. 11a, b) are nearly the same as that of CTRL $\left(\sim-7 \times 10^{-4} \mathrm{~s}^{-1}\right.$; Fig. $\left.8 \mathrm{c}\right)$ over the upstream side of the southern CMR. The return flow in H80 and H60, however, is weaker and restricted to a relatively smaller area than in the CTRL experiment (see 0600 UTC in Figs. 11a, b). During the next four hours (see 0800 and 1000 UTC in Figs. 11a, b), the region of low-level convergence in H80 and H60 is still on the windward slope near the mountain peak and somewhat stronger than in the CTRL experiment (Figs. 8e, g). The difference in the magnitude of the lowlevel convergence is mainly caused by the dynamicallydriven return flow. In the CTRL experiment, the return flow becomes well developed at 1000 UTC 12 June (Fig. 8g) on the windward slope, where the wind direction veers from a southwesterly wind to a southerly wind. This veering of the wind direction suggests that the air is favored to move around the CMR in CTRL rather than proceed over the ridge in H80 and H60. During this period, the low-level convergence in CTRL slightly weakens and is shifted northwestward compared to Fig. 8c. For the H80 and H60 experiments, however, the dynamically-driven return flow is much weaker and the convergence center associated with the southwesterly flow is located on the upstream side of the mountain ridge (Figs. 11a, b). As a result, the simulated MCS in $\mathrm{H} 80$ and $\mathrm{H} 60$ propagates north-northeastward in the vicinity of the mountain peak after it encounters the Taiwan terrain as shown in Figs. 12a and b.

The above results reveal that the flow regime over southern CMR tends to shift from "flow-around" regime to "flow-over" regime when the terrain height is reduced to 80 or $60 \%$ of that in the CTRL simulation. For a fixed CAPE $\left(\sim 2858 \mathrm{~J} \mathrm{~kg}^{-1}\right)$ in this case study, the values of $F_{w}$ for $\mathrm{H} 80$ and $\mathrm{H} 60$ are about 0.416 and 0.555 , which fall into regime II as classified by Chen and Lin (2005a). This flow regime is characterized by a long-lasting orographic convective system near the mountain peak. Figures $13 \mathrm{a}$ and $\mathrm{b}$ show that the significant accumulated precipitation associated with the MCS in the H80 and H60 simulations is primarily along the peak of the terrain (i.e., over the southern CMR in the present case).

With further reduction of the terrain height in the H40 and $\mathrm{H} 20$ simulations, the low-level convergence (Figs. 11c, d) is much smaller in magnitude than that in CTRL experiment at 0600 UTC 12 June (Fig. 8c) over the windward side of the CMR. The northward deflection of the flow west of southern CMR is not as clearly visible (Figs. 11c, d), suggesting that the air at lower levels could flow over the lowered mountain in the $\mathrm{H} 40$ and $\mathrm{H} 20$ experiments. The time sequence of rainwater mixing ratio at $z=1 \mathrm{~km}$ (Figs. 12c, d) shows that the simulated MCS in $\mathrm{H} 40$ and $\mathrm{H} 20$ is advected northeastward by the basic flow, which is characterized by a downstream-propagating convective system toward the southeastern part of the island. Obviously, these two simula- 

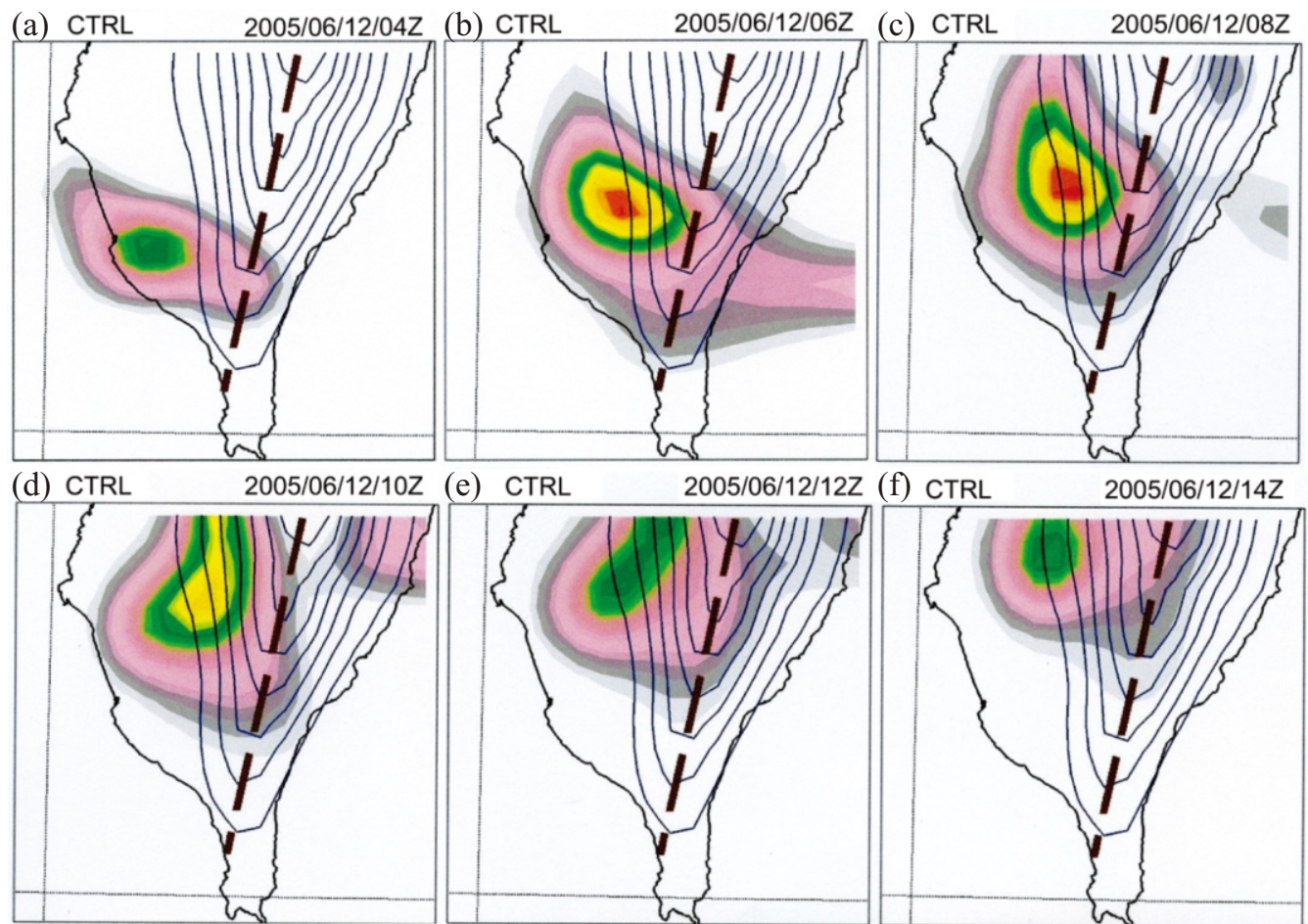

\section{(e) CTRL}

2005/06/12/12Z (f) CTRL

2005/06/12/14Z
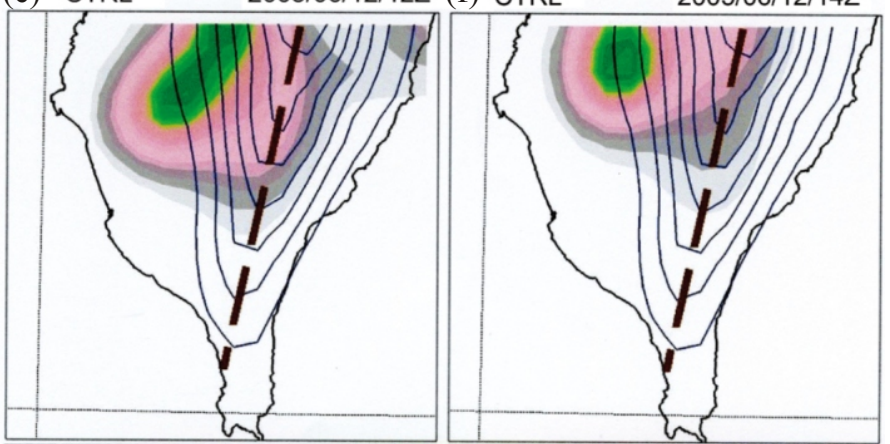

1.0

2.0

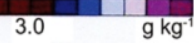

Fig. 9. Simulated rain water mixing ratio $\left(\mathrm{g} \mathrm{kg}^{-1}\right)$ at $z=1 \mathrm{~km}$ in CTRL for (a) 0400, (b) 0600, (c) 0800, (d) 1000, (e) 1200, and (f) $1400 \mathrm{UTC}$ on $12 \mathrm{June}$ 2005. Taiwanese terrain heights (thin lines) in CTRL start from $300 \mathrm{~m}$ and have a contour interval of $300 \mathrm{~m}$. The bold dashed lines indicate the mountain peak of Taiwan.
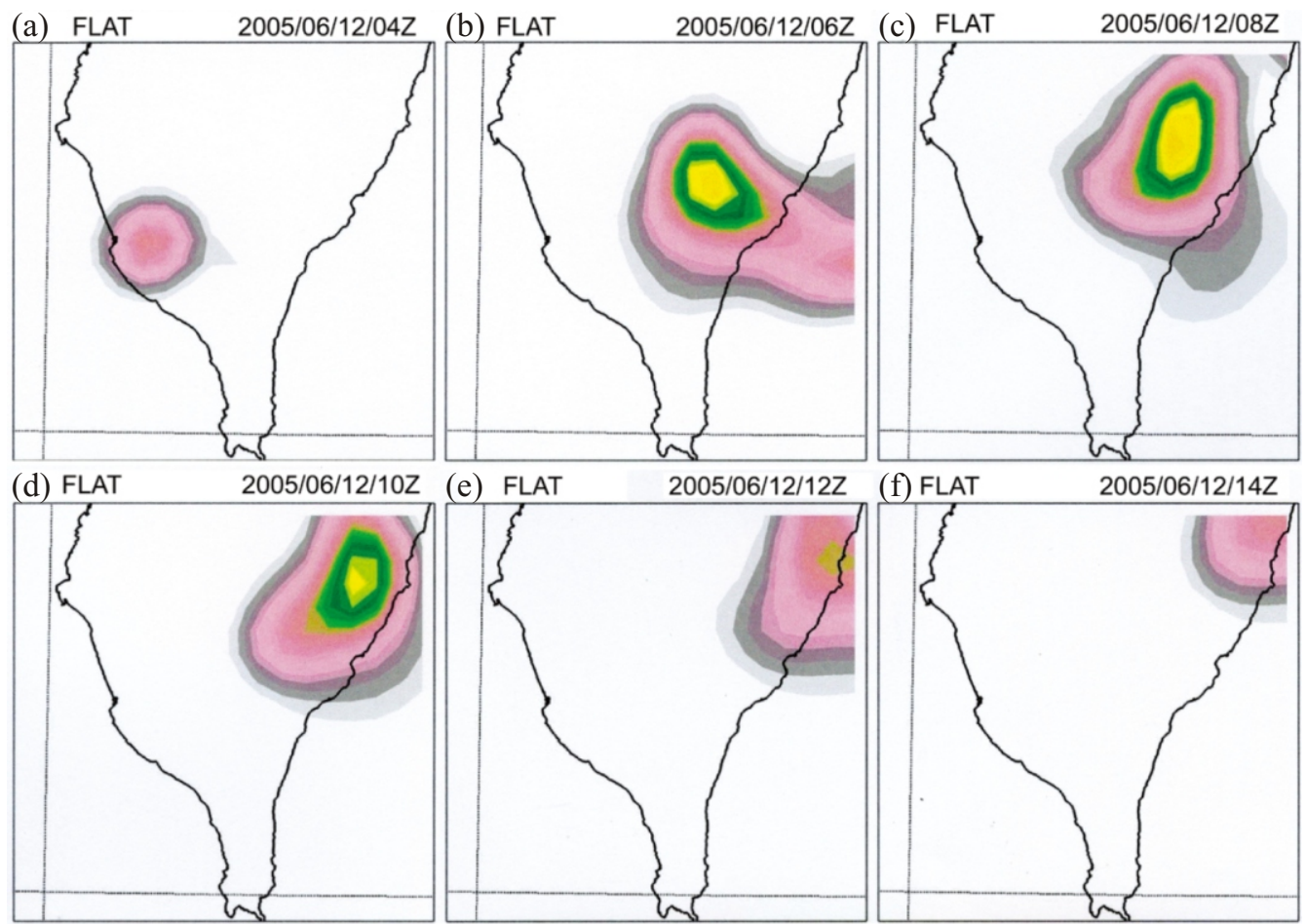

10

2.0

3.0

$\mathrm{g} \mathrm{kg}^{-1}$

Fig. 10. As in Fig. 9, except for experiment FLAT. 
(a) Exp. $\mathrm{H} 80$
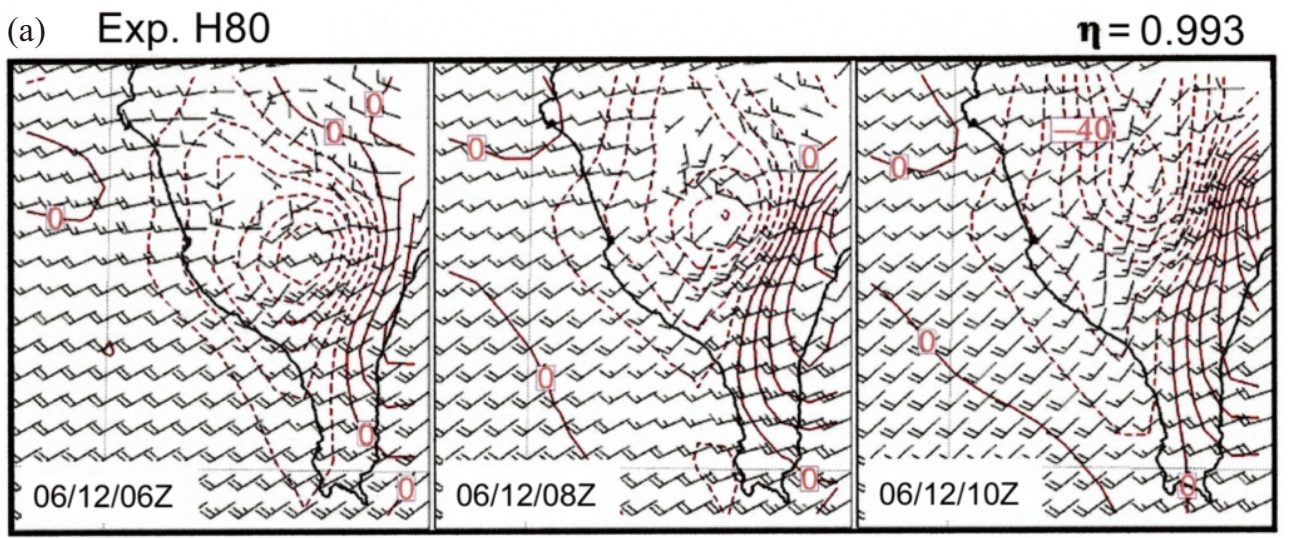

(b) Exp. H60

$\boldsymbol{\eta}=0.993$
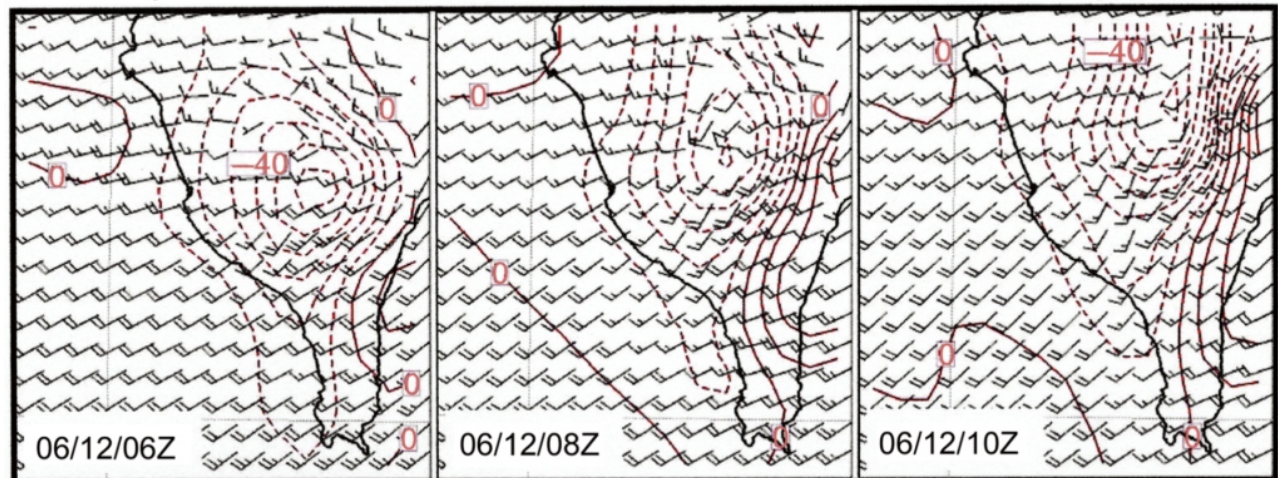

(c) Exp. $\mathrm{H} 40$

$\eta=0.993$
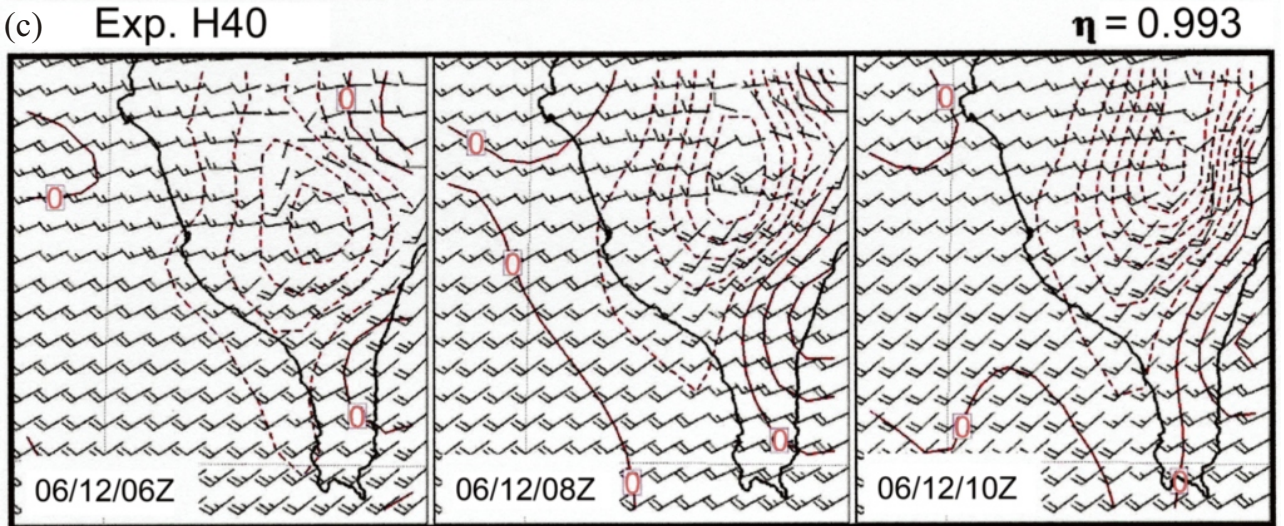

(d) Exp. $\mathrm{H} 20$

$\eta=0.993$

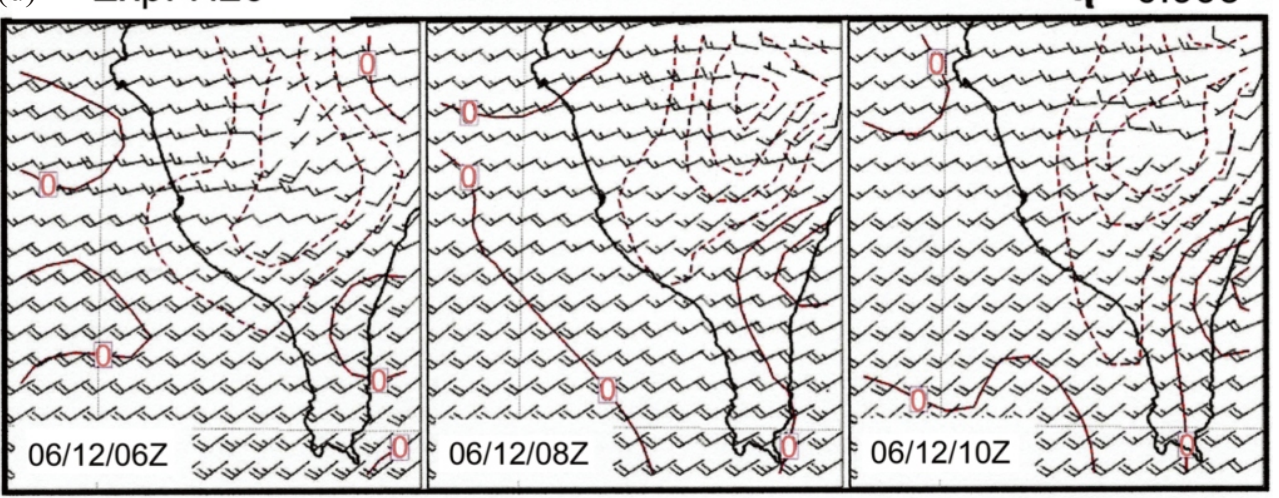

Fig. 11. Simulated wind vectors (half barb $=2.5 \mathrm{~m} \mathrm{~s}^{-1}$ and full barb $=5 \mathrm{~m} \mathrm{~s}^{-1}$ ) and horizontal divergence fields (with contour interval of $10 \times 10^{-5} \mathrm{~s}^{-1}$ ) at $\eta=0.993$ for (a) H80, (b) H60, (c) H40, and (d) H20 at 0600, 0800, and 1000 UTC 12 June 2005. 
(a) Exp. $\mathrm{H} 80$

rain water mixing ratio at $z=1 \mathrm{~km}$

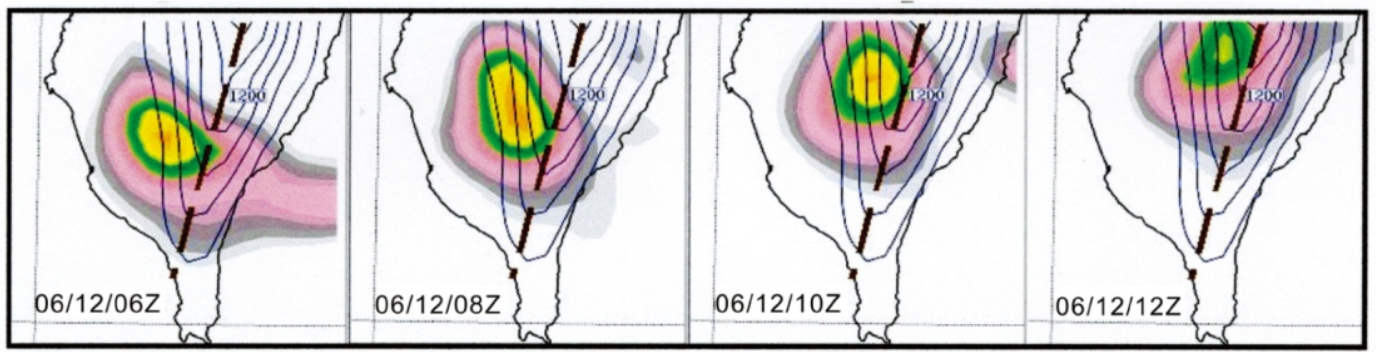

(b) Exp. H60

rain water mixing ratio at $z=1 \mathrm{~km}$

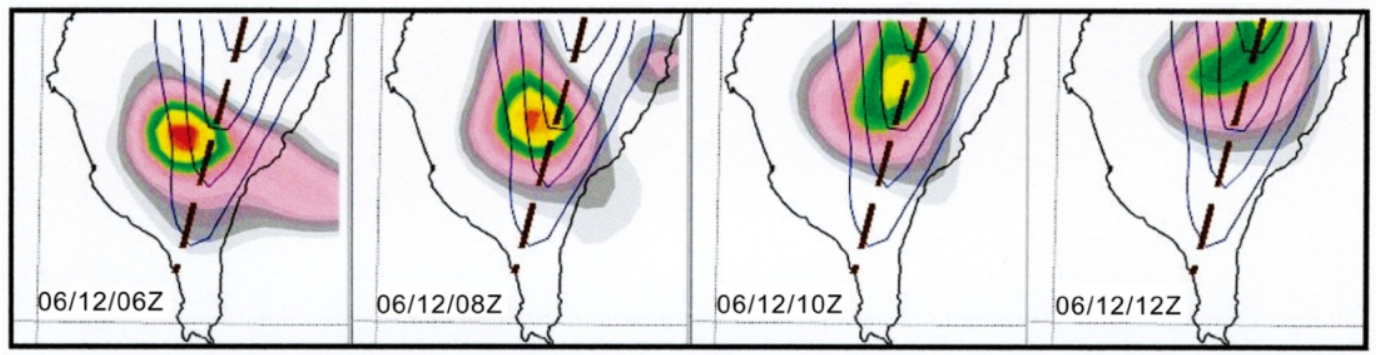

(c) Exp. H40

rain water mixing ratio at $z=1 \mathrm{~km}$

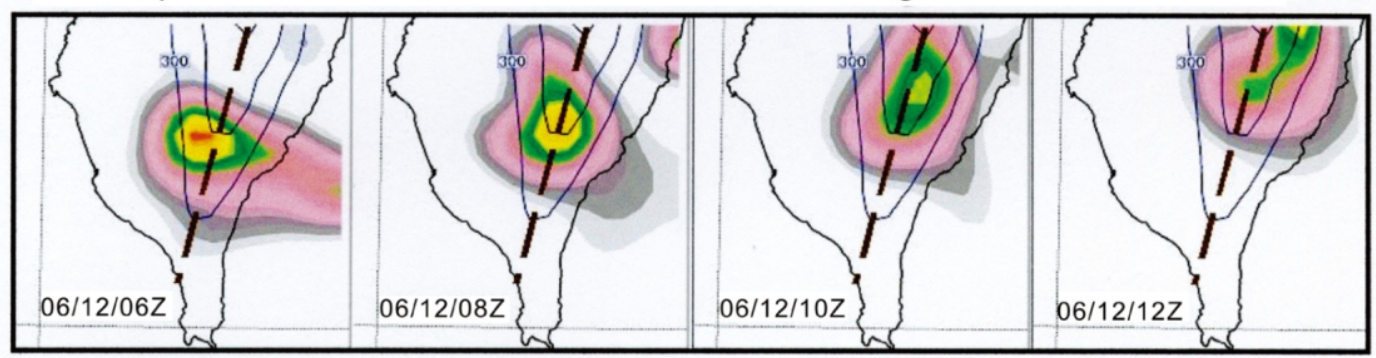

(d) Exp. H20

rain water mixing ratio at $z=1 \mathrm{~km}$

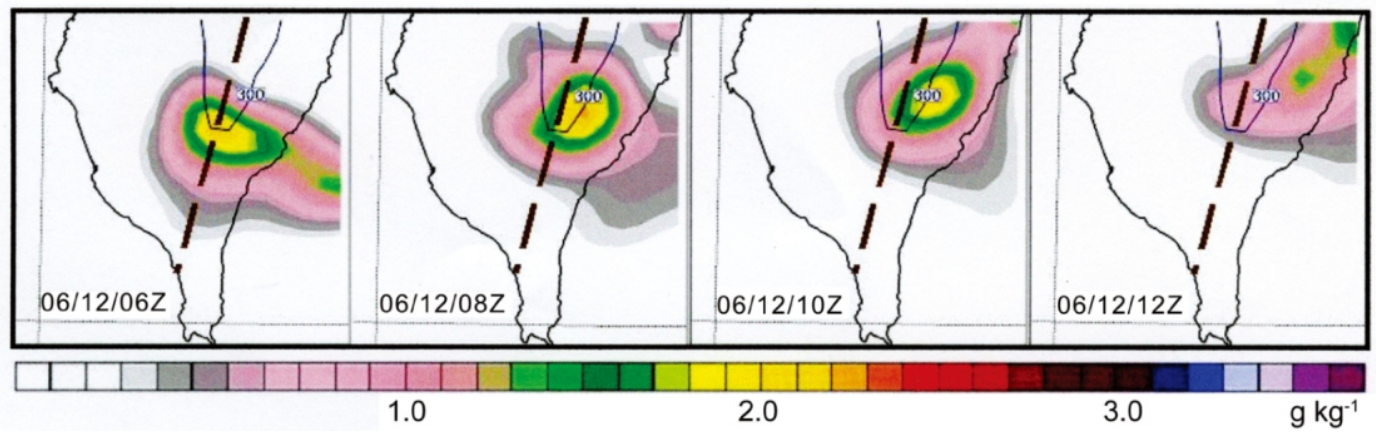

Fig. 12. Simulated rain water mixing ratio $\left(\mathrm{g} \mathrm{kg}^{-1}\right)$ at $z=1 \mathrm{~km}$ for (a) H80, (b) H60, (c) H40, and (d) H20 at 0600, 0800, 1000 , and $1200 \mathrm{UTC} 12 \mathrm{June}$ 2005. The terrain heights (thin lines) in these sensitivity studies start from $300 \mathrm{~m}$ and have a contour interval of $300 \mathrm{~m}$. The bold dashed lines indicate the mountain peak of terrain.

tions fall into the regime of flow over the mountain. The relatively large values of the $F_{w}$ for $\mathrm{H} 40$ and $\mathrm{H} 20(\sim 0.833$ and 1.666) imply that the airflow belongs to the regime III as proposed by Chen and Lin (2005a). The 12-h total rainfall in the $\mathrm{H} 40$ and $\mathrm{H} 20$ simulations indicates not only a lower amount over the mountain slope but also no rain over the plain area of southwestern Taiwan (Figs. 13c, d). This smaller amount of rainfall is due to the reduced elevation of the CMR and the associated lifting effect. As the simulated MCS propagates downstream, another heavy rainfall maximum is produced over southeastern Taiwan along the Mei$\mathrm{Yu}$ front. The results of the H40 and H20 experiments demonstrate that the southern CMR plays a key role in producing the torrential rainfall of the present event. The values of rainwater mixing ratio at $z=1 \mathrm{~km}$ in $\mathrm{H} 20$ (Fig. 12d) are much weaker and has a different orientation as compared 
(a) $06 / 1200 Z \sim 06 / 1212 Z \quad H 80$

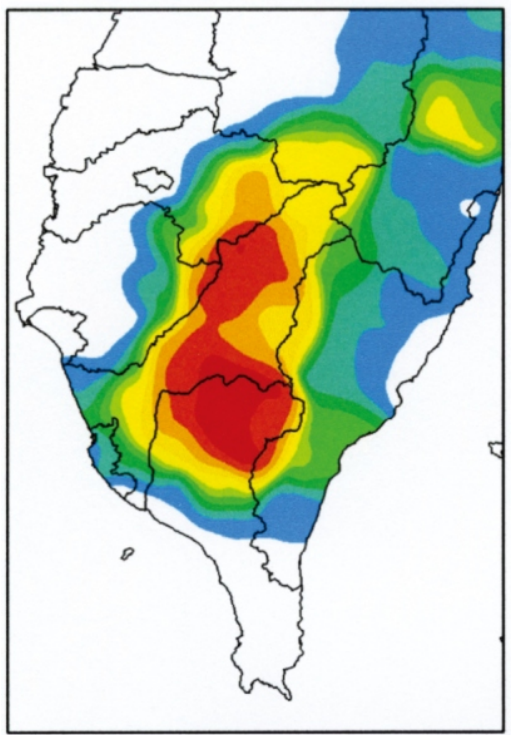

(c) $06 / 1200 Z \sim 06 / 1212 Z \quad H 40$

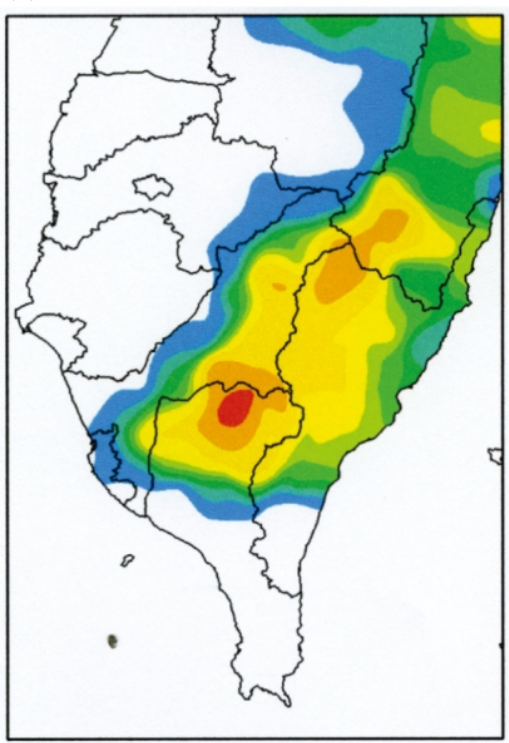

(b) $06 / 1200 Z \sim 06 / 1212 Z \quad H 60$

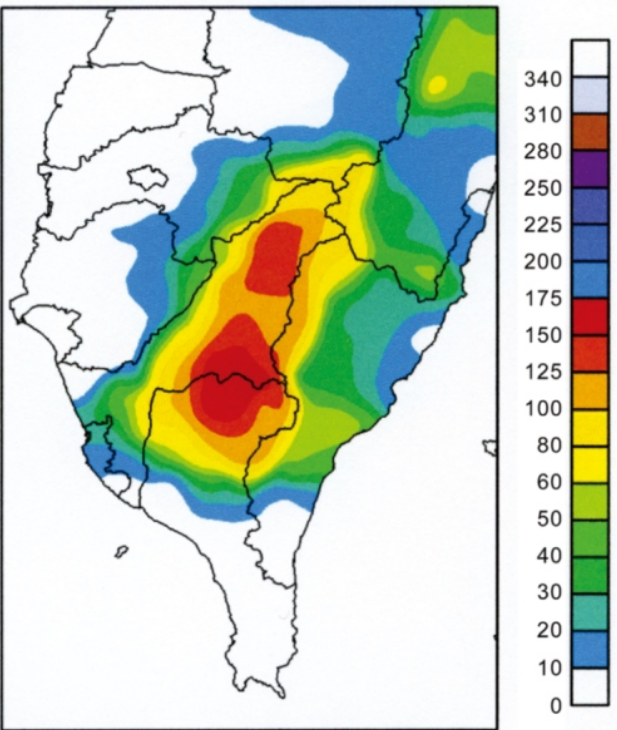

(d) $06 / 1200 Z \sim 06 / 1212 Z \quad H 20$

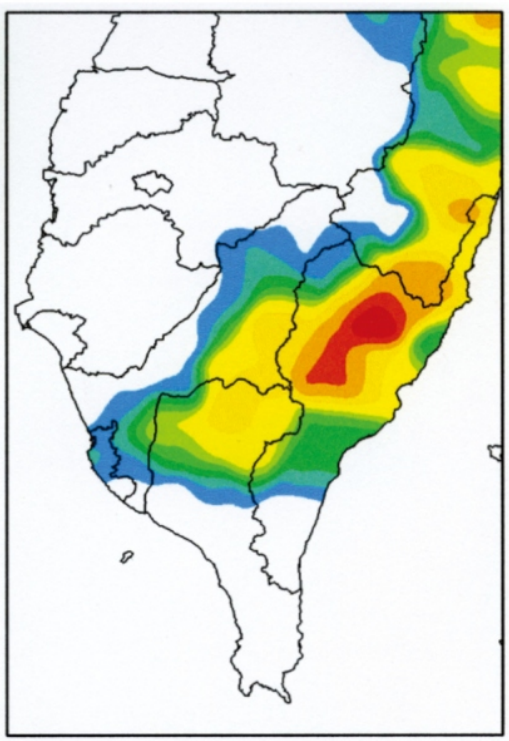

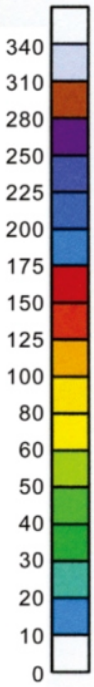

Fig. 13. As in Fig. 6, except for experiments (a) H80, (b) H60, (c) H40, and (d) H2O.

to the CTRL simulation (Fig. 9). With a higher (lower) terrain, the shape of the larger rainwater mixing ratio zone (e.g., $>2.0 \mathrm{~g} \mathrm{~kg}^{-1}$ ) associated with the MCS experiences greater (less) distortion upon encountering southern CMR.

To provide a more quantitative evaluation of rainfall simulation performance, the Equitable threat scores (ETS) and bias scores for the accumulated rainfall simulations during 0000 - 1200 UTC 12 June 2005 are shown for precipitation thresholds of $30,40,50,60,70,80,90$, and $100 \mathrm{~mm}$ in Fig. 14. The ETS scores show that the CTRL performs significantly better than the reduced-terrain experiments for all thresholds. The highest ETS of CTRL exceeds 0.48 at the $60 \mathrm{~mm}$ threshold, and are about 0.45 at the 40,50 , and $70 \mathrm{~mm}$ thresholds in this period. The bias scores indicate that the CTRL simulated rainfall is slightly overforecast at large thresholds but does a fairly good job for thresholds smaller than $80 \mathrm{~mm}$. In contrast, $\mathrm{H} 40$ and $\mathrm{H} 20$ produce too little rain at all thresholds resulting in severe underforecasting (low bias scores) and low ETS scores in Fig. 14. It should be noted that $\mathrm{H} 80$ has relatively low ETS scores compared to CTRL, but good bias scores for thresholds of 90 and $100 \mathrm{~mm}$. This result implies that the total number of rain gauge precipitation observations above the given threshold is compatible with the H80's simulation, but not in the correct location. The heavier rainfall in $\mathrm{H} 80$ occurred over the mountain peaks rather than on the windward slope is a large liability. 


\section{SUMMARY}

This series of numerical simulations examines the physical processes responsible for the torrential rainfall associated with a mesoscale convective system along the Mei$\mathrm{Yu}$ front that resulted in extreme heavy rainfall over southwestern Taiwan on 12 June 2005. The numerical experiments are performed with a horizontal grid size of $9 \mathrm{~km}$ using the Advanced Research WRF (WRF-ARW) modeling system, version 2.0.3. All the 48-h model simulations begin at 1200 UTC 11 June 2005.

In the control experiment with full Taiwan terrain, the simulated accumulated rainfall agrees well with the observed rainfall during 0000 - 1200 UTC 12 June, especially for the areal distribution of the heavier rainfall which occurs over both the windward slope and the plain area in southwestern Taiwan. The MCS in the control experiment propagates northward along the slope of the southern CMR. In the simulation without the Taiwan terrain, the simulated MCS moves downstream along the Mei-Yu front and implies that Taiwan's terrain plays a significant role in the MCS propagation. A conceptual model of the propagation of a MCS to different $F_{w}$ values (by changing the Taiwan terrain height) is shown in Fig. 15. The MCS was initiated around 1800 UTC 11 June over the southern Taiwan Strait, where was favorable for the development of a deep convection with strong convective instability below $850 \mathrm{hPa}$ (CAPE $\left.>2800 \mathrm{~J} \mathrm{~kg}^{-1}\right)$. The value of $F_{w}$ associated with the basic flow over the southern CMR is about 0.333 in the control simulation $\left(U \sim 7.5 \mathrm{~m} \mathrm{~s}^{-1}, N_{w} \sim 0.009 \mathrm{~s}^{-1}\right.$, and $\left.h \sim 2500 \mathrm{~m}\right)$. This airflow is deflected by the CMR with a low-level return flow on the northern side of the MCS. The low-level convergence between the dynamically-driven return flow and the incoming southwesterly flow is favorable for the northward propagation of the MCS. A flow-around regime upstream of the CMR is found in the present case, which falls into the regime I as proposed by Chen and Lin (2005a). Consequently, the torrential rain is produced over the windward slope and adjacent plains.

Sensitivity experiments in which Taiwan's terrain is artificially reduced indicate that as the terrain height decreases, the airflow with higher value of $F_{w}$ tends to shift to a higher number of the flow regime. For experiments with the terrain height decreased to $80 \%\left(F_{w} \sim 0.416\right)$ or $60 \%\left(F_{w}\right.$ $\sim 0.555$ ) of that in the control simulation, the accumulated rainfall associated with the simulated MCS primarily occurs along the mountain peak of the southern CMR. The simulated MCS propagates north-northeastward in the vicinity of the mountain peak after it encounters the Taiwan terrain (see Fig. 15). The airflow in these sensitivity experiments belongs to the flow regime II, which is characterized by a long-lasting orographic convective system near the mountain peak.

When the terrain height is further reduced to $40 \%\left(F_{w}\right.$ $\sim 0.833)$ or $20 \%\left(F_{w} \sim 1.666\right)$ of that in the control simulation, the airflow at lower level could flow over the lowered mountain with weaker convergence and smaller wind deflection over the windward slope of southern CMR. A downstream-

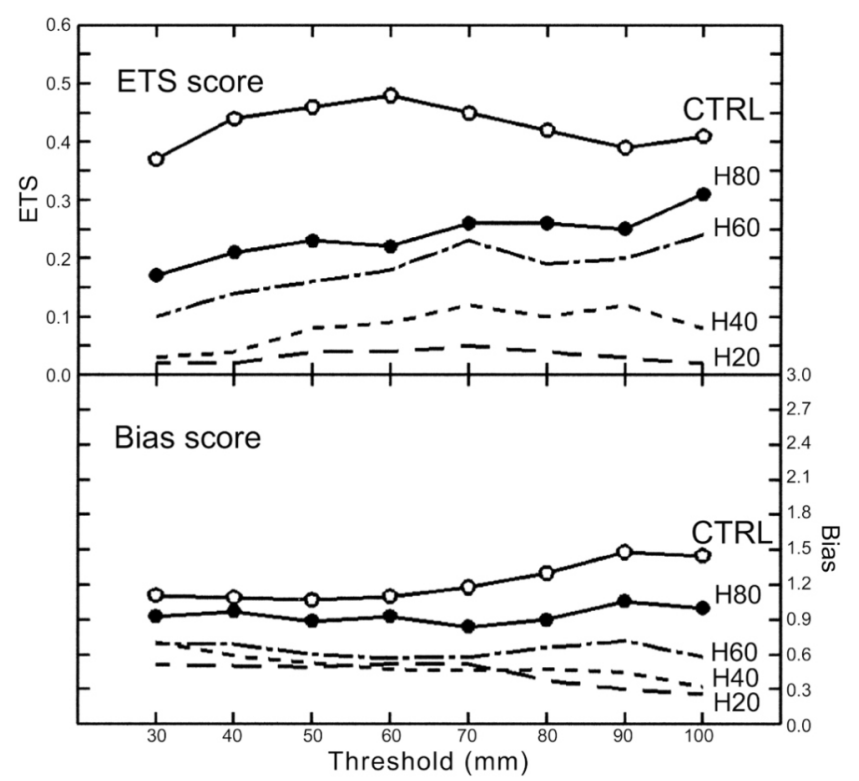

Fig. 14. Equitable threat scores (upper panel) and bias scores (lower panel) for the accumulated rainfall simulations during 0000 - 1200 UTC 12 June 2005 from CTRL (open circles), H80 (filled circles), H60 (dot-dashed), H40 (short dashed), and H20 (long dashed).

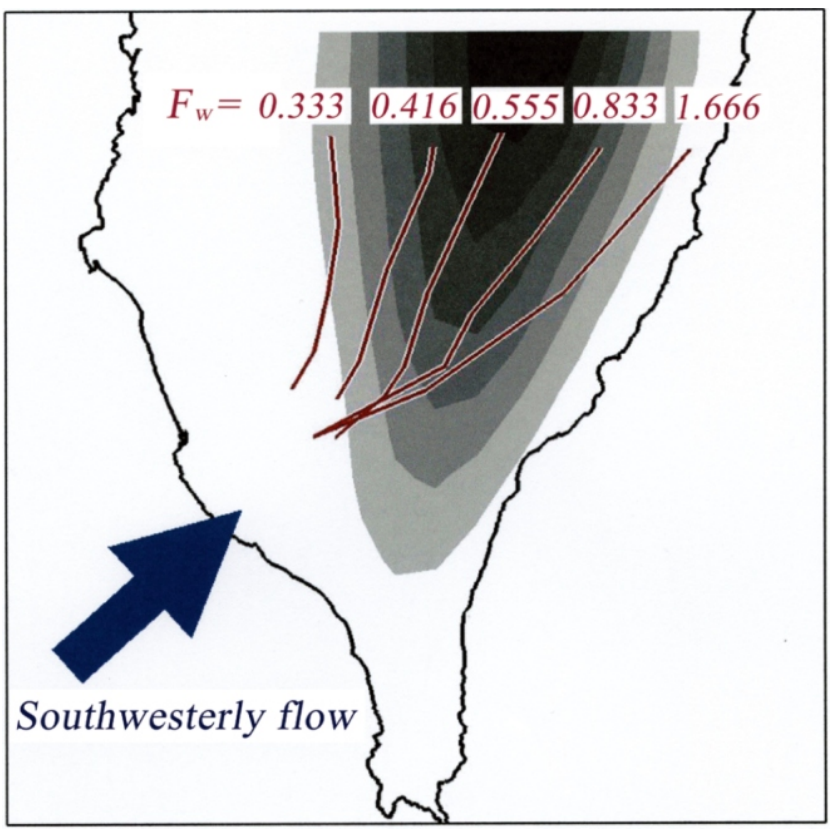

Fig. 15. Schematic diagram describing the propagation of a MCS (thin lines) in the potentially unstable southwesterly flow (bold arrow) over the mountain ridge in southern Taiwan for experiments CTRL $\left(F_{w}=\right.$ $0.333), \mathrm{H} 80\left(F_{w}=0.416\right), \mathrm{H} 60\left(F_{w}=0.555\right), \mathrm{H} 40\left(F_{w}=0.833\right)$, and $\mathrm{H} 20$ $\left(F_{w}=1.666\right)$. 
propagating MCS is simulated toward southeastern Taiwan in these latter experiments (see Fig. 15), which fall into the regime III as classified by Chen and Lin (2005a). Due to the significant reduction of terrain height, the rainfall amount is much smaller over the mountain slope(s) and no rain is produced over the western plain area on the windward side of the island. The northward propagating MCS, which is mainly caused by the influence of southern CMR, is an important factor for producing torrential rains over southwestern Taiwan during 0000 - 1200 UTC 12 June 2005. The results of the above numerical experiments also suggest that the flow regimes proposed by Chen and Lin (2005a) are useful for determining the location of heavy rainfall associated with a MCS moving toward southwestern Taiwan under the influence of a low-level southwesterly flow. However, there are still some model discrepancies between the simulated precipitation and the observations, such as the high rainfall bias in eastern Taiwan and the different locations of rainfall maxima over southwestern Taiwan. These differences are likely caused by the different positions of clouds between model forecast and the actual Mei-Yu front. One of the major reasons for the high rainfall bias over eastern Taiwan is that a 9-km grid size is not fine enough to resolve the terrain features responsible for the rain shadow on the lee (eastern) side of the the CMR. Further advances in high-resolution atmospheric modeling could be of great value for quantitative precipitation forecast in mountainous regions over Taiwan. In addition, as shown in Xiao et al. (2005) and Xiao and Sun (2007), better representation of convective systems in model initial conditions plays a key role in the improvement of the rainfall forecast, especially if the Doppler radar data are assimilated into a high-resolution mesoscale model through a three-dimensional variational data assimilation (3DVAR) system. These efforts are ongoing to simulate more cases and examine in detail to address the physical processes while MCSs move toward Taiwan during the Mei-Yu season.

Acknowledgements The authors thank two anonymous reviewers for their insightful and constructive comments that have helped improve the content and presentation of the manuscript. Some assistance from S. Y. Liou in the graphics is also appreciated. This work is supported by the National Science Council of Taiwan Grant NSC 95-2625-Z052-001, NSC 96-2625-Z-052-007, NSC 97-2625-M-052007, and NSC 97-2111-M-052-001.

\section{REFERENCES}

Arya, S. P., 1988: Introduction to Micrometeorology. Academic Press, 303 pp.

Chen, C. S., W. S. Chen, and Z. Deng, 1991: A study of a mountain-generated precipitation system in northern Taiwan during TAMEX IOP 8. Mon. Wea. Rev., 119, 2574-2607, doi: 10.1175/1520-0493(1991)119<2574:ASOAMG>2.0. $\mathrm{CO} ; 2$. [Link]
Chen, G. T. J., 1983: Observational aspects of the Mei-Yu phenomena in subtropical China. J. Meteorol. Soc. Jpn., 61, 306-312.

Chen, G. T. J., 1992: Mesoscale features observed in the Taiwan Mei-Yu season. J. Meteorol. Soc. Jpn., 70, 497-516.

Chen, G. T. J., and C. C. Yu, 1988: Study of low-level jet and extremely heavy rainfall over northern Taiwan during Mei-Yu season. Mon. Wea. Rev., 116, 884-891, doi: 10.1175/1520-0493(1988)116<0884:SOLLJA>2.0.CO;2. [Link]

Chen, G. T. J., C. C. Wang, and D. T. W. Lin, 2005: Characteristics of low-level jets over Northern Taiwan in MeiYu season and their relationship to heavy rain events. Mon. Wea. Rev., 133, 20-43, doi: 10.1175/MWR-2813.1. [Link]

Chen, G. T. J., C. C. Wang, and L. F. Lin, 2006: A diagnostic study of a retreating Mei-Yu front and the accompanying low-level jet formation and intensification. Mon. Wea. Rev., 134, 874-896, doi: 10.1175/MWR3099.1. [Link]

Chen, S. H. and J. Dudhia, 2003: Annual report: WRF physics. Air Force Weather Agency, 38 pp, Available online at http://www.mmm.ucar.edu/wrf/users/docs /wrf-phy.html.

Chen, S. H. and Y. L. Lin, 2005a: Effects of moist Froude number and CAPE on a conditionally unstable flow over a mesoscale mountain ridge. J. Atmos. Sci., 62, 331-350, doi: 10.1175/JAS-3380.1. [Link]

Chen, S. H. and Y. L. Lin, 2005b: Orographic effects on a conditionally unstable flow over an idealed three-dimensional mesoscale mountain. Meteorol. Atmos. Phys., 88, 1-21, doi: 10.1007/s00703-003-0047-6. [Link]

Chen, Y. L. and J. Li, 1995: Large-scale conditions favorable for the development of heavy rainfall during TAMEX IOP 3. Mon. Wea. Rev., 123, 2978-3002, doi: 10.1175/15200493(1995)123<2978:LSCFFT>2.0.CO;2. [Link]

Chiao, S. and Y. L. Lin, 2003: Numerical modeling of an orographically enhanced precipitation event associated with tropical storm rachel over Taiwan. Weather Forecast., 18, 325-344, doi: 10.1175/1520-0434(2003)018<0325: NMOAOE $>2.0 . \mathrm{CO} ; 2$. [Link]

Chu, C. M. and Y. L. Lin, 2000: Effects of orography on the generation and propagation of mesoscale convective systems in a two-dimensional conditionally unstable flow. $J$. Atmos. Sci., 57, 3817-3837, doi: 10.1175/1520-0469(2001) 057<3817:EOOOTG>2.0.CO;2. [Link]

Dodson, R. and D. Marks, 1997: Daily air temperature interpolated at high spatial resolution over a large mountainous region. Clim. Res., 8, 1-20, doi: 10.3354/cr008001. [Link]

Dudhia, J., 1989: Numerical study of convection observed during the winter monsoon experiment using a mesoscale two-dimensional model. J. Atmos. Sci., 46, 3077-3107, doi: 10.1175/1520-0469(1989)046<3077:NSOCOD $>2.0$. $\mathrm{CO} ; 2 .[\underline{\text { Link}}]$

Hong, S. Y., J. Dudhia, and Y. Noh, 2003: A new vertical diffusion package with explicit treatment of the entrainment processes. Proc. Int. Workshop on NWP Models for Heavy 
Precipitation in Asia and Pacific Areas, Tokyo, Japan, Japan Meteorological Agency, 52-58.

Hong, S. Y., J. Dudhia, and S. H. Chen, 2004: A revised approach to ice microphysical processes for the bulk parameterization of clouds and precipitation. Mon. Wea. Rev., 132, 103-120, doi: 10.1175/1520-0493(2004)132<0103: ARATIM $>2.0 . \mathrm{CO} ; 2$. [Link]

Jou, B. J. D., 1997: Atlas of Radar Images of Mesoscale Convective Systems in the Taiwan Mei-Yu Season. Department of Atmospheric Science, National Taiwan University, $144 \mathrm{pp}$.

Jou, B. J. D. and S. M. Deng, 1992: Structure of a low-level jet and it's role in triggering and organizing moist convection over Taiwan: A TAMEX case study. Terr. Atmos. Ocean. Sci., 3, 39-58.

Kain, J. S., 2004: The Kain-Fritsch convective parameterization: An update. J. Appl. Meteorol., 43, 170-181, doi: 10.1175/1520-0450(2004)043<0170:TKCPAU>2.0.CO;2. [Link]

Kuo, Y. H. and G. T. J. Chen, 1990: The Taiwan Area Mesoscale Experiments (TAMEX): An overview. Bull. Amer. Meteor. Soc., 71, 488-503, doi: 10.1175/1520-0477(1990)071 $<0488$ :TTAMEA>2.0.CO;2. [Link]

Lin, Y. L., 2007: Mesoscale Dynamics. Cambridge University Press, $632 \mathrm{pp}$.

Lin, Y. L., S. Chiao, T. A. Wang, M. L. Kaplan, and R. P. Weglarz, 2001: Some common ingredients for orographic flooding and heavy rainfall. Weather Forecast., 16, 633660, doi: 10.1175/1520-0434(2001)016<0633:SCIFHO > 2.0.CO;2. [Link]

Liou, C. S., J. H. Chen, C. T. Terng, F. J. Wang, C. T. Fong, T. E. Rosmond, H. C. Kuo, C. H. Shiao, and M. D. Cheng, 1997: The second-generation global forecast system at the Central Weather Bureau in Taiwan. Weather Forecast., 12, 653-663. [Link]
Mlawer, E. J., S. J. Taubman, P. D. Brown, M. J. Iacono, and S. A. Clough, 1997: Radiative transfer for inhomogeneous atmospheres: RRTM, a validated correlated- $k$ model for the long-wave. J. Geophys. Res., 102, 16663-16682, doi: 10.1029/97JD00237. [Link]

Skamarock, W. C., J. B. Klemp, J. Dudhia, D. O. Gill, D. M. Barker, W. Wang, and J. G. Powers, 2005: A description of the Advanced Research WRF Version 2. NCAR Technical Note, NCAR/TN-468+STR, 88 pp.

Wang, C. C., G. T. J. Chen, T. C. Chen, and K. Tsuboki, 2005: A numerical study on the effects of Taiwan topography on a convective line during the Mei-Yu season. Mon. Wea. Rev., 133, 3217-3242, doi: 10.1175/MWR3028.1. [Link]

Watanabe, H. and Y. Ogura, 1987: Effects of orographically forced upstream lifting on mesoscale heavy precipitation: A case study. J. Atmos. Sci., 44, 661-675, doi: 10.1175/ 1520-0469(1987)044<0661:EOOFUL >2.0.CO;2. [Link]

Xiao, Q. and J. Sun, 2007: Multiple-radar data assimilation and short-range quantitative precipitation forecasting of a squall line observed during IHOP_2002. Mon. Wea. Rev., 3381-3404, doi: 10.1175/MWR3471.1. [Link]

Xiao, Q., Y. H. Kuo, J. Sun, W. C. Lee, E. Lim, Y. R. Guo, and D. M. Barker, 2005: Assimilation of Doppler radar observations with a regional 3DVAR system: Impact of Doppler velocities on forecasts of a heavy rainfall case. J. Appl. Meteorol., 44, 768-788, doi: 10.1175/JAM2248.1. [Link]

Yeh, H. C. and Y. L. Chen, 2002: The role of offshore convergence on coastal rainfall during TAMEX IOP 3. Mon. Wea. Rev., 130, 2709-2730, doi: 10.1175/1520-0493(2002)130 $<2709$ :TROOCO>2.0.CO;2. [Link]

Yoshizaki, M., T. Kato, Y. Tanaka, H. Takayama, Y. Shoji, and H. Seko, 2000: Analytical and numerical study of the 26 June 1998 orographic rainband observed in western Kyushu, Japan. J. Meteorol. Soc. Jpn., 78, 835-856. 